\title{
CERÁMICAS CON DECORACIÓN SIMBÓLICA Y CORDÓN INTERIOR PERFORADO PROCEDENTES DE VARIAS CUEVAS SITUADAS EN LA SUBBÉTICA CORDOBESA
}

\section{CERAMICS WITH DECORATION AND PERFORATED INNER CORD FROM VARIOUS CAVES LOCATED IN THE CORDOBAN SUBBETICA MOUNTAIN RANGE}

\author{
por \\ BEATRIZ GAVILÁN CEBALLOS \\ JUAN CARLOS VERA RODRÍGUEZ
}

\begin{abstract}
RESUMEN: Estudiamos una serie de cerámicas procedentes de las cuevas de los Murciélagos (Zuheros), de el Muerto (Carcabuey) y Negra (Rute), provincia de Córdoba, que muestran la presencia de un cordón interior perforado situado inmediatamente debajo del labio $\mathrm{y}$, en determinados casos, representaciones de «oculados». Tanto la forma de las vasijas, la tipología de sus asas y las decoraciones no simbólicas, apuntan hacia una adjudicación neolítica. La presencia de temas simbólicos conlleva nuevos planteamientos sobre el tema oculado en el Arte Esquemático andaluz.
\end{abstract}

\begin{abstract}
We study a group of pottery fragments found at the caves of «Murciélagos» (Zuheros), «el Muerto» (Carcabuey) and «Negra» (Rute), in the province of Córdoba. All of them show an internal perforated cord just under the rim. Sometimes this feature is combined with «ocular» representations in the neck of the vessels. Their forms, tipology of handles and non-simbolic decoration, lead us to consider them as Neolithic. The analisys of these Neolithic simbolical potteries opens new perspectives about ocular theme in Andalousian Schematic Art.
\end{abstract}

Dentro de la relativa uniformidad cultural que se observa en lo concerniente a la ergología de los yacimientos neolíticos del Subbético cordobés, destacan, por determinadas particularidades morfológicas de caracter funcional y de temática decorativa que presentan, que no a nivel tipológico ni técnico, trece vasijas de cerámica, incompletas, de las que se conservan fragmentos pertenecientes a bordes, cuellos y galbos, procedentes de la Cueva de los Murciélagos (Zuheros), de la Cueva del Muerto (Carcabuey) y de la Cueva Negra (Rute). Sus implicaciones funcionales y su interés a la hora de poner en relación elementos de cultura material, con motivos del arte esquemático parietal y mueble, nos ha impulsado a la realización de este trabajo.

La Cueva de los Murciélagos de Zuheros, sobradamente conocida en la bibliografía científica, ha sido objeto de cuatro campañas de excavación realizadas por A.M ${ }^{\mathrm{a}}$. Vicent y A.M ${ }^{\mathrm{a}}$. de la Quadra en 1962 (Quadra y Vicent, 1964), por A.M ${ }^{\mathrm{a}}$. Vicent y A.M . Muñoz en 1969 (Vicent y Muñoz, 1973) y dos 
campañas de Excavación Arqueológica de Urgencia dirigidas por quien suscribe en 1990, que incluyó la limpieza superficial de la misma, y en 1991 (Gavilán, 1991; Gavilán y Vera, 1992).

En la Cueva Negra de Rute no se ha realizado, por el momento, ningún tipo de actividad arqueológica científica, conociéndose de ella un lote de material neolítico, fruto de recogidas superficiales llevadas a cabo sin ningún tipo de control, que tuvimos la oportunidad de analizar con motivo de la realización de la Tesis Doctoral de uno de nosotros (Gavilán, 1989 b), y lo mismo cabe decir de la Cueva del Muerto (Carcabuey), descubierta en 1986, habiendo proporcionado un enterramiento múltiple con un ajuar poco diagnóstico para permitir una adjudicación cultural fiable y precisa, y un conjunto de items adjudicables al Neolítico Medio-Final unos y otros al Calcolítico (Gavilán, 1986; 1987; 1989 b). Para una más extensa documentación sobre estas cavidades, remitimos a la bibliografía citada.

\section{CARACTERISTICAS DEL MATERIAL}

Dado que el número de vasijas, trece en total, no permite un estudio estadístico y que es imprescindible individualizar sus decoraciones, presentamos la descripción pormenorizada de cada una en el catálogo final, comenzando por los ejemplares de la Cueva de los Murciélagos de Zuheros ( $\left.\mathrm{n}^{\circ} 1-11\right)$, y el ejemplar de Cueva Negra $\left(\mathrm{n}^{\circ} 12\right)$ y, finalmente, el de la Cueva del Muerto $\left(\mathrm{n}^{\circ} 13\right)$.

A la vista del catálogo, puede apreciarse cómo estos ejemplares reúnen una serie de características comunes:

a.- Se trata de fragmentos pertenecientes a vasijas de Muy Buena Calidad (bruñida, espatulada y alisada muy fina) o de Buena Calidad (alisada fina y alisada) en la superficie exterior, estando representados los siguientes acabados: bruñido -seis ejemplares-, espatulado -tres-, alisado muy fino -uno- y alisado fino tres-. En la superficie interior tampoco encontramos acabados pertenecientes a la Baja Calidad, predominan los grupos de acabados que integran la Buena Calidad y contamos con: espatulado -uno-, alisado fino -siete- y alisado -cuatro-, además de una superficie erosionada. Como se observa, todas estas vasijas han sido cuidadosamente tratadas en lo que al acabado de las superficies se refiere, siendo de mejor calidad la cara exterior que la interior, tónica general en las cerámicas neolíticas y en ningún caso el tratamiento de ambas caras de los recipientes se ha descuidado, como lo demuestra la inexistencia de acabados de Baja Calidad (alisada tosca, tosca y muy tosca).

b.- En lo que se refiere a la cocción, el tipo más abundante es la alternante -siete-, seguida del nervio de cocción -cuatro- y, por último del fuego reductor -dos-, estando ausente la cocción oxidante. De este modo, los fuegos mixtos (alternante + nervio de cocción) predominan, puesto que los tenemos en once de los trece ejemplares estudiados.

c.- Los desgrasantes pertenecen, mayoritariamente, al grupo de los Medios: finos -nueve ejemplares, medios -tres- y, por último, los muy finos -uno-. Están ausentes los no apreciables y los que forman el grupo de los desgrasantes Gruesos (grueso y muy grueso).

d.- En cuanto a los bordes, la dirección recta está presente en cinco ejemplarẹs y la saliente en cuatro, en un caso es entrante y en los tres que restan no ha sido posible determinarla, mientras que el labio es plano en siete ejemplares, apuntado en cuatro y redondeado en uno. El diámetro, en los fragmentos que nos han permitido hallarlo, es, igualmente, muy homogéneo. Contamos con dos ejemplares que han ofrecido una medida de $13 \mathrm{~cm}$; en tres, mide $9 \mathrm{~cm}$. y, en los que quedan, en uno mide $13^{\prime} 3 \mathrm{~cm}$., en otro $13^{\prime} 4$, en otro $9^{\prime} 6 \mathrm{~cm}$. y $15^{\prime} 9 \mathrm{~cm}$. en el que resta. Se trata, por lo tanto, de diámetros de tamaño medio, oscilando entre $\operatorname{los} 9 \mathrm{~cm}$. de mínimo y $15^{\prime} 9 \mathrm{~cm}$. de máximo. En la mayoría de los ejemplares el diámetro del labio describe una elipse, y no un círculo, forma a la que coadyuva en parte, como veremos, la presencia de un cordón interior perforado. 
e.- Los sistemas de prehensión y suspensión (S.P.S.) más abundantes son las asas y, dentro de ellas, predominan las asas verticales multiforadas, destacando el ejemplar $n^{\circ} 6$ (Fig. 8, $n^{\circ} 6.510$, láms. VI-VIII) por presentar dos asas verticales y una horizontal, siendo las tres multiforadas. Además, contamos con un asa de cinta vertical y con un mamelón redondeado macizo de caracter no funcional. Junto a estos, están presentes, también, los agujeros de suspensión, que aparecen en cuatro ocasiones, situados siempre próximos tanto al borde como al asa, sea ésta del tipo que sea.

f.- En los siete ejemplares decorados, la técnica empleada es la incisión, combinándose con la impresión en tres casos. Los temas describen líneas incisas horizontales situadas debajo del borde, mientras que en el galbo contamos con líneas incisas verticales que abarcan toda la porción conservada (Fig. 4, nº . 4.711, lám. IV), líneas incisas horizontales y verticales, ángulos en serie y líneas horizontales de las que parten líneas oblicuas en sentido ascendente, $y$, por último, impresiones oblicuas opuestas, que no llegan a formar una espiga y bandas incisas verticales rellenas de impresiones con la misma disposición anterior.

En cuanto a los fragmentos de cuellos decorados, hay que decir que muestran composiciones variadas dentro de una misma temática. En el vaso $n^{\circ} 6$ (Fig. 8, n ${ }^{\circ} .6 .510$; láms. VI-VIII) se trata de un esteliforme -un ojo- sobre el que aparecen, próximas al borde, dos líneas incisas -a modo de ceja- mientras que en el $\mathrm{n}^{\circ} 13$ (fig. $5, \mathrm{n}^{\circ} 13$ ) los motivos se articulan de una manera un tanto inusual en lo que a decoración de recipientes cerámicos se refiere, al estar los temas esteliformes (en realidad, una impecable representación de oculado) «enmarcados» por líneas horizontales -las cejas- y haces de líneas verticales. Contamos, además, con el ejemplar $\mathrm{n}^{\circ} .7$ (Fig. 5, $\mathrm{n}^{\circ}$ 6; láms. IX-X) cuya inclusión dentro de los temas oculados es innegable, con los ojos, las cejas e incluso la nariz claramente representados, e igualmente hemos de resaltar el fragmento ${ }^{\circ} 8$ (Fig. $6, n^{\circ} 7$; lám. XI) con tres impresiones describiendo un arco en el cuello, que paralelizado en motivo decorativo y situación del mismo con los anteriores, nos sugieren los «rayos» de un esteliforme -un ojo- encontrándonos ante una composición similar, máxime cuando este fragmento también presenta dos líneas incisas horizontales situadas debajo del borde -la ceja-, aunque no podamos asegurarlo al contar con una porción temática tan reducida.

g.- En cuanto a las formas que presentan estos recipientes, aunque no contamos con ningún ejemplar completo, hemos podido determinar, cuando esto ha sido posible, que siempre se trata de formas compuestas, bien con cuellos en forma de trapecio con la base mayor hacia arriba y con el galbo en forma de elipse con el eje mayor en horizontal, bien a base de un cuello en forma de rectángulo con el eje mayor horizontal y un galbo en forma de una elipse con el eje mayor igualmente horizontal. Se trata, en definitiva, de vasijas que, a juzgar por las porciones de éstas con que contamos, pertenecen a la Forma C-1.2. (derivadas de la elipse con el eje mayor horizontal más un trapecio con la base mayor hacia arriba), y a la Forma C-1.0.1. (derivadas de la elipse con el eje mayor horizontal más un rectángulo con el eje mayor horizontal) (Gavilán, 1989 b).

h.- Todos los ejemplares presentan por el interior, a un nivel inmediatamente inferior al labio, un cordón perforado, que en los casos en que se conservan los S.P.S., parte de una asa y finaliza en la opuesta, estando presente, por lo tanto, en un sólo lateral del interior de la vasija. En el ejemplar $n^{\circ} 6$, que cuenta con tres S.P.S., el asa horizontal se encuentra, por el exterior, en la cara opuesta a la del cordón interior perforado.

i.- Se produce la asociación significativa, siempre en un mismo lateral del recipiente, del cordón perforado al interior y de la decoración al exterior del borde, cuello y asas. Esta coincidencia, independientemente del tema que sea, no es casual, sino totalmente intencionada, ya que, aunque en algún caso, la decoración afecta también a la cara opuesta, sólo lo hace a partir del arranque del cuello hacia el galbo, no contándose, además, con ningún ejemplar decorado mediante esteliformes u oculados en que éstos se encuentren en la cara opuesta al cordón interior. Las vasijas más significativas en este sentido, quizá también por ser las más completas, son la $\mathrm{n}^{\circ} 1$ y la $\mathrm{n}^{\circ} 6$ (fig. $3, \mathrm{n}^{\circ} 3.643$ y fig. $8, \mathrm{n}^{\circ} 6.510$, respectivamente), 
ya que hemos de advertir que la vasija $\mathrm{n}^{\circ} 2$ (fig. $4, \mathrm{n}^{\circ} 4.711$ ) es una reconstrucción ideal realizada a partir de los fragmentos conservados. En los restantes ejemplares que presentan decoración, al no conservarse más que una parte del cuello de la vasija, no podemos saber si la cara opuesta se decoró con la misma composición o con otra distinta, pero en cualquier caso, suponemos, basándonos en las composiciones citadas, que la decoración desarrollaría temas diferentes.

j.- Al margen de estas cuestiones, nos parece interesante resaltar que dentro de la Subbética cordobesa sean tres cavidades diferentes las que han proporcionado, por el momento, recipientes con las características que aquí damos a conocer. Este hecho pone de manifiesto la existencia de fuertes contactos a una escala que va más allá de lo puramente material y, en este sentido, nos reafirma en la unidad cultural que venimos propugnando para el Neolítico del subbético cordobés, aunque con las lógicas diferencias entre unos yacimientos y otros, según la entidad de los mismos y su situación dentro de dicha área geográfica. (Gavilán, 1989 b).

\section{PARALELOS Y ADJUDICACION CULTURAL}

Al tratarse de un material no contextualizado, hemos de acudir forzosamente a los paralelos para proponer una adscripción de estas vasijas a un momento cultural y, en este sentido, nos enfrentamos con un fuerte impedimento al no haber encontrado en la bibliografía recipientes cerámicos que reúnan los dos caracteres que aquí damos a conocer.

En lo que se refiere a la presencia de un cordón interior perforado, hay que decir que no conocemos ni un solo ejemplar publicado hasta el momento, que cuente con él (sabemos de la presencia de un fragmento de cerámica con esta misma particularidad procedente del Boquete de Zafarraya, Málaga, aún inédito).

Sí se documenta la existencia de vasijas que presentan una serie de perforaciones, técnicamente idénticas a los agujeros de suspensión, realizadas inmediatamente debajo del labio y que abarcan la mitad del perímetro de la vasija, como la procedente de la Cueva de las Palomas, en Teba (Málaga) (Baldomero, 1978), para la que propone una adjudicación del Calcolítico basándose en el conjunto de material restante, mayoritariamente de este momento cultural, que fue extraído por unos particulares sin ningún tipo de control científico. En la excavación de esta cavidad (Ferrer y Marqués, 1978), se documentó la presencia de materiales claramente neolíticos junto a otros calcolíticos, de manera que juzgamos más probable la atribución del ejemplar a un momento culturalmente neolítico o de tradición de éste (Ibidem), más que a la etapa cultural propuesta. De hecho, en la misma Cueva de los Murciélagos de Zuheros tenemos varios fragmentos de borde con estos «agujeros de suspensión» en serie situados debajo del labio, de los que se ha publicado algún caso (Vicent y Muñoz, 1973: fig. 11, n²18), en el que coincide, además, la presencia de una típica asa vertical multiforada.

Es posible que exista una relación funcional entre estas vasijas y las que nos ocupan, pues las diferencias entre ambos tipos son más de técnica de ejecución que formales, sustituyéndose el cordón por simples perforaciones, que de la misma manera, sólo atañen claramente a la mitad del perímetro de la vasija y se sitúan inmediatamente debajo del labio, contando algunas de las nuestras, además, con un agujero de suspensión.

En consecuencia, no somos partidarios de atribuir los recipientes procedentes de las cuevas de los Murciélagos, del Muerto y Negra al Calcolítico, por los motivos antes expuestos en relación con el citado recipiente malagueño, que además, presenta una tipología muy semejante a los cordobeses. En efecto, tanto la forma de estas vasijas como la decoración que ofrecen algunas de ellas, nos indican que están en perfecta consonancia con el resto de los materiales cerámicos que aparecen en el Neolítico Medio y/o Final detectado en la Subbética cordobesa. 
Creemos, por tanto, que deben ser las formas de estos recipientes, los sistemas de prehensión y suspensión, así como los temas decorativos presentes en algunos de ellos, los que arrojen algo de luz a la hora de proponer una adjudicación cultural.

Las formas que presentan estas vasijas son frecuentes dentro de los conjuntos neolíticos andaluces, pudiéndose subdividir el tipo en variantes muy concretas. Se trata de formas compuestas cuyo galbo deriva bien de la elipse bien de la esfera, más un trapecio o un rectángulo que da lugar al cuello de la vasija.

Formas globulares con cuello cilíndrico se constatan en Nerja en el Neolítico Antiguo, mientras que en el Medio y en el Reciente se dan con cuello troncocónico invertido (Pellicer y Acosta; en Jordá, 1986), que equivaldría a nuestro trapecio con la base mayor hacia arriba (Gavilán, 1989 b). Más próxima a nuestros yacimientos se encuentra la Cueva del Plato, en Castillo de Locubín, que cuenta con una vasija de forma similar que ha sido adjudicada (Navarrete y Carrasco, 1978) al Neolítico Medio, paralelizable con formas procedentes de los niveles IV y V de la Cueva de los Murciélagos de Zuheros, en la que encontramos, casi a lo largo de toda la estratigrafía obtenida en 1969 (Vicent y Muñoz, 1973), formas compuestas que, fechadas en el Neolítico Medio, son variantes de nuestro tipo.

Pasando a las decoraciones, los motivos que presentan las vasijas $n^{\circ} 2$ (Fig. $4, n^{\circ} 4.711$ ) y la $n^{\circ} 1$ (Fig. $3, n^{\circ} 3.643$ ) resultan bastante usuales dentro de los conjuntos neolíticos contextualizados, de manera que sólo citaremos algunos casos. En la Cueva de la Carihuela están presentes, en el Estrato IV de la Cámara «D», varios fragmentos con una decoración similar, incluso la forma del galbo coincide con la que ofrece nuestro ejemplar $n^{\circ} 2$. Este estrato pertenece al Neolítico Final (Pellicer, 1964), mientras que en Nerja los encontramos desde el Neolítico Antiguo hasta el Reciente, cueva en que son más abundantes durante la fase Media (Pellicer y Acosta; en Jordá, 1986). Por su parte, las bandas rellenas, igualmente abundantes, las vemos representadas en el Neolítico Medio de Carihuela (Navarrete, 1976) y en el de Nerja (Pellicer y Acosta; en Jordá, 1986).

Independientemente de los paralelos más arriba citados, en los yacimientos en cueva situados en la Subbética de Córdoba contamos con un número nada desdeñable de materiales en los que aparecen temas decorativos similares a algunos de los que muestran estas vasijas, así como formas y sistemas de prehensión y suspensión paralelizables (Gavilán, 1989 b).

En cuanto a los esteliformes, se documentan en Nerja en el Neolítico Medio (Pellicer y Acosta; en Jordá, 1986), en Carihuela en el estrato XI del Neolítico Final (Pellicer, 1964), así como un ejemplar en las excavaciones de la cercana Cueva de los Mármoles (Asquerino, 1986-87), aún no adjudicado a una fase concreta del Neolítico. Este tema se documenta también en varias cuevas cuyos restos materiales carecen de estratigrafía, como en las de los Botijos (Olaria, 1976), la Cueva de la Murcielaguina (Gavilán, 1989 a), la Sima del Carburero (Menjibar y otros, 1981), etc., pero en contextos claramente neolíticos.

Entre los paralelos temáticos más semejantes que hemos encontrado en la bibliografía, aparte de los ejemplares neolíticos de Nerja y de la Sima del Carburero, se cuentan las denominadas «cerámicas simbólicas» calcolíticas, en las que esteliformes y oculados constituyen los temas fundamentales. Sin embargo, hemos de señalar una diferencia sustancial en lo que se refiere a la tipología de dichas cerámicas calcolíticas y las que damos a conocer en este trabajo. Las «cerámicas simbólicas» presentan formas de tendencia elíptica con el eje mayor horizontal principalmente, o bien, de tendencia esférica, troncocónica, etc., a la par que carecen de cuello desarrollado y tipo alguno de asa. A estas diferencias formales, hay que sumar las funcionales, ante la ausencia del cordón interior perforado.

En cuanto a los sistemas de prehensión y suspensión, nos encontramos ante un tipo de asa, la multiforada de pequeñas dimensiones que arranca directamente del labio de la vasija y finaliza en el arranque del galbo, que resulta ser frecuente dentro del Neolítico en la Subbética cordobesa, del que es una característica definitoria (Gavilán, 1989 b). Este tipo de asa multiforada no es tan usual en otros 
yacimientos neolíticos andaluces, en los que abundan, como en el Neolítico cordobés, asas dobles distintas a las que nos ocupan, junto a asas multiforadas de una morfología igualmente diferente. En Dehesilla, las asas dobles se documentan en el Neolítico Antiguo A (Acosta y Pellicer, 1990), en Carihuela están presentes en las distintas fases del Neolítico (Pellicer, 1964), siendo frecuentes en numerosos yacimientos cuyos materiales han sido adjudicados a la fase Media y/o Final del Neolítico. En Nerja las multiforadas con más de dos perforaciones, se encuentran a partir del Neolítico Antiguo (Pellicer y Acosta; en Jordá, 1986: 401). Junto a estos paralelos, hemos de destacar un ejemplar semejante a los nuestros procedente de la Cueva de la Mujer, en Alhama (Navarrete, 1976: Lám. CCLVI, nº 7; McPherson, 1870). Finalmente, asas multiforadas verticales de pequeño tamaño, idénticas en este caso, las hemos documentado en la propia Cueva de los Murciélagos de Zuheros durante la campaña de 1991, en la Unidad Estratigráfica 36, correspondiente a las primeras fases deposicionales de la ocupación neolítica del yacimiento, a la que hemos denominado «Neolítico A» (Gavilán y Vera, 1992: 28).

Por todo ello, y pese a lo insólito que podrían parecer en principio algunos de los temas presentes en estas vasijas -caso de los esteliformes y los oculados enmarcados por líneas horizontales y verticales-, somos partidarios de proponer una adjudicación cultural del Neolítico Medio y/o Final para estas vasijas con presencia del cordón interior perforado, adjudicación hacia la que apuntan tanto las características de la pasta y su factura, como determinados temas decorativos, las formas de estas vasijas y los sistemas de prehensión y suspensión que presentan, teniendo en cuenta, sobre todo, que en la misma Cueva de los Murciélagos de Zuheros, variantes de estas formas y algunos de los temas que vemos en estas vasijas, excepción hecha de los esteliformes y oculados, son usuales dentro del contexto neolítico de este yacimiento, resultando ser, por lo tanto, el mejor apoyo en el que podemos basarnos para tal adjudicación.

\section{CONSIDERACIONES FINALES}

Como se desprende de todo lo anteriormente expuesto, el caracter inusual de estas vasijas es innegable tanto por la presencia del cordón interior perforado, que por sí solo justifica sobradamente un estudio concreto y aparte del resto del conjunto material conocido de estas tres cuevas, como por los temas decorativos desarrollados en algunas de ellas y la combinación decoración y tema decorativo/cordón interior perforado en el mismo lateral de la vasija.

En cuanto a la funcionalidad de estos recipientes, aunque no podamos determinarla, creemos que está en relación directa con el cordón interior perforado. Opinamos que estos recipientes pudieron utilizarse no como «coladores», pero sí para filtrar y verter líquido por el cordón interior perforado, impidiendo éste la salida de algún residuo sólido. No creemos que el cordón interior perforado tuviese la finalidad de soporte de algún tipo de cierre o tapadera del recipiente, ya que en este caso carecerían de sentido las perforaciones y el cordón abarcaría, de manera más eficaz, todo el perímetro interior del borde y no sólo su mitad.

De otro lado, es posible que funcionalidad y temas decorativos en algunos ejemplares, caso de los «esteliformes» y oculados, nos estén indicando que estas vasijas se destinaban a algún uso especial, no habitual. Nos parece fuera de duda la no utilización de estas vasijas como recipientes de «cocina», ya que sus características de acabado, con superficies generalmente bruñidas que impiden la filtración de líquido a través de las paredes de la vasija, formas, cordón interior perforado y tema decorativo, no concuerdan con dicha utilización. A este respecto, y teniendo en cuenta la semejanza temática que ofrecen algunas de estas vasijas con las denominadas «cerámicas simbólicas», no creemos que deban considerarse como elementos de carácter exclusivamente ritual, polémica en la que no entraremos, por parecernos que ya ha sido rechazada con suficiente fundamento (Martín y Camalich, 1982). No obstante, hay que reconocerles un matiz exclusivo y concederles una especificidad en sentido conceptual de la que carecen otros productos 
cerámicos, al contar con una decoración propia del arte esquemático parietal y mueble al que se suma el cordón interior perforado, lo que nos hace suponer una funcionalidad diferente, que no tiene necesariamente por qué ser ritual.

La aludida ausencia de un contexto estratigráfico para los materiales cordobeses, hace que no puedan ser taxativamente relacionadas bien con zona de hábitat, bien con conjuntos funerarios. En todo caso, pese a la existencia de un enterramiento múltiple en la Cueva del Muerto y a que en la Cueva de los Murciélagos de Zuheros se ha detectado la presencia de restos óseos humanos, tanto en estratigrafía (Gavilán y Vera, 1992), como en zonas libres de sedimento, en ninguna de las dos cavidades las vasijas ofrecen relación alguna con los restos óseos detectados, siendo Murciélagos, por otro lado, una cavidad con fuerte ocupación de hábitat. Si por paralelismo temático las cotejamos con la procedencia contextual de las «cerámicas simbólicas» calcolíticas, queda clara su mayor frecuencia dentro de los conjuntos funerarios formando parte del ajuar, pero se documentan también, y cada día más, en lugares de habitación (Martín y Camalich, 1982).

En otro orden de cosas, opinamos que el simbolismo de algunos de estos ejemplares parece claro. Así, en lo que concierne especificamente a los motivos aislados, la presencia de esteliformes en vasijas neolíticas no es, como vimos, insólita, aunque tampoco es muy frecuente; pero es a nivel compositivo donde vemos que no estamos ante simples esteliformes aislados, ya de por sí culturalmente significativos, sino ante una temática más compleja en la que se articulan elementos simples para representar los rasgos faciales -ojos, cejas, nariz-con tendencia realista o naturalista dentro de su esquematismo; tema simbólico que, en etapas inmediatamente posteriores, se relaciona con, o está presente en determinados elementos cultuales, religiosos, representados generalmente en otras materias primas soportes, excepción hecha de las «cerámicas simbólicas» procedentes del Sureste principalmente, aunque se documentan en diferentes puntos del territorio peninsular, en las que claramente se desarrolla la temática de determinados ídolos en piedra, terracota y/o hueso.

Al hilo de lo expuesto, hay que tener en cuenta que es posible que algunos de los fragmentos cerámicos neolíticos que presentan como tema decorativo un esteliforme, bien pudieran contar con otro situado al lado del conservado, ofreciendo, igualmente, una temática más compleja conceptualmente que el simple esteliforme. En este sentido, nos parece interesante destacar los fragmentos con esteliformes procedentes de la Cueva de los Botijos. En ambos casos se aprecia cómo, en la porción conservada, los esteliformes se encuentran enmarcados por una línea quebrada de la que parten, en un ejemplar, incisiones cortas y, en otro, impresiones. A uno de estos fragmentos (Olaria, 1977: Lám. IV, nº 7), Navarrete le da una orientación completamente diferente, situando verticalmente el trazo de mayor longitud de la línea (1976: lám. CCCXXXVII, $\mathrm{n}^{\circ} 6$ ), orientación ésta que nos parece mucho más acertada que la primera propuesta. Asimismo, queremos señalar que el tema que Navarrete describe como «roseta» (1976: 360) presente en el fragmento $n^{\circ} 2$ (1976: Lám. CCCXXI), y que para Olaria es un esteliforme esquematizado (1977: 39), para nosotros tiene perfecta cabida dentro de los esteliformes. Cabría plantearse, además, la posibilidad de que en las dos piezas de Botijos, el mismo tema se repita al lado, como ocurre en los fragmentos procedentes de Nerja, Sima del Carburero, el $n^{\circ} 6$ de Murciélagos y el de la Cueva del Muerto, constituyendo indiscutibles representaciones de oculados.

Estos oculados que se plasman a base de representaciones pareadas de esteliformes, enmarcados, además, por líneas, bandas, etc., horizontales y/o verticales, y que responden a simbolismos y abstracciones complejas, anteceden y deben relacionarse con las representaciones que durante el Calcolítico, con presencia de otros detalles ya, como los tatuajes faciales y, en algunos casos, el peinado, responden a objetos cultuales -como son los ídolos-falange, ídolos sobre huesos largos y, posiblemente, determinados ídolos-cilindro, en lo que se refiere a objetos muebles-, independientemente ya de la materia prima soporte elegida en cada caso, y a las representaciones de «ídolos-oculados» presentes en las paredes de numerosas 
cuevas y abrigos rocosos. A estos elementos, puramente cultuales, hay que añadir las cerámicas simbólicas de Monte de Outeiro (Shubart, 1965), Los Millares (Arribas y otros, 1979), Almizaraque (Delibes y otros, 1984), el sepulcro Domingo I (Ferrer, 1977), el poblado de Sala I (Gonçalves, 1989), etc.

La presencia de temáticas cultuales, pero desarrolladas sobre cerámicas neolíticas como las que presentamos ahora y, sobre todo, el ejemplar de la Cueva de Nerja por las semejanzas que ofrece con los nuestros y proceder de un contexto estratigráfico perteneciente al Neolítico Medio, nos lleva a proponer un origen que arranca, al menos, desde dicha fase neolítica, no sólo ya para los motivos esteliformes, sino también para la simbología que representan los oculados, aunque sea en el Calcolítico cuando alcancen su florecimiento y mayor difusión.

Las últimas tendencias hacia la adjudicación cultural del Arte Esquemático Parietal (Carrasco y otros, 1985) apuntan hacia unos inicios anteriores al Neolítico, desarrollándose plenamente durante dicho período, sobre todo durante la fase Media, al menos en el caso de las Sierras Subbéticas, habiéndose acudido para ello a la presencia de determinados temas de este tipo de arte, destacando los antropomorfos y los esteliformes entre otros, en las cerámicas, como en las de la Cueva del Agua de Prado Negro, Carihuela, etc., que han servido, acertadamente desde nuestro punto de vista, para proponer dicha adjudicación cultural. Sin embargo, para temas relacionados con las representaciones de «ídolos» y «oculados» se propone siempre un origen ya más tardío, Calcolítico, para lo que se acude, generalmente, a las cerámicas simbólicas de Los Millares (Ibidem), y en efecto, la mayoría de dichos temas parecen corresponder a la citada etapa cultural, a tenor de la presencia, en la mayor parte de los oculados pintados, de los característicos «tatuajes faciales», paralelizables, además, con buen número de los ídolos realizados sobre soportes muebles.

Pero ante lo expuesto, resulta lógico plantearse la adjudicación que, por regla general, se atribuye a todos los «oculados» representados en el interior de las cuevas y abrigos rocosos. En este caso, nos estamos refiriendo a un tipo concreto de oculado, como es el documentado en la propia Cueva de los Murciélagos y el de la Cueva de la Murcielaguina (Bernier y Fortea, 1968-69), que constituyen, según ambos investigadores, una variante dentro de la morfología de los ídolos-placa. Sin embargo, para nosotros, la simplicidad de estas representaciones plásticas no pueden constituir tal variante, puesto que en ellos están ausentes la casi totalidad de los caracteres que definen el tipo, sino que, al contrario, responden a una representación de oculados del mismo tipo que los representados en las cerámicas neolíticas, muy simples, pero con los rasgos esenciales que definen al tema, nariz, ojos y cejas, cuyo significado combinado es conocido y reconocido iconográficamente por los integrantes de un determinado grupo neolítico. Este proceso, podría relacionarse con el mismo fenómeno de abstracción, una parte por el todo, que se observa en determinados ídolos calcolíticos (Hurtado, 1978: 359).

Ello no quiere decir que estemos proponiendo un origen Neolítico para la totalidad del tema sobre soportes parietales, sino sencillamente, como acabamos de indicar, un inicio anterior al Calcolítico para este determinado tipo simple de oculado que acabamos de definir, constituyendo una composición simbólica que, nacida en el seno de las primeras comunidades productoras, evolucionará y se desarrollará, ya ampliamente, en diferentes objetos cultuales a lo largo de la Edad del Cobre.

\section{CATALOGO}

$\mathrm{N}^{\circ}$ 1.- Doce fragmentos de una misma vasija de la que se conservan distintas porciones de borde con cuello y galbo (Fig. 3, $\mathrm{n}^{\circ}$ 3.643). Tanto la superficie exterior como la interior han sido objeto de un magnífico tratamiento, bruñida y espatulada respectivamente. La cocción es alternante y el desgrasante medio. Al exterior, el color de la pasta responde a dos tonalidades diferentes, beige y gris, mientras que el interior, muy homogéneo, presenta una tonalidad negruzca. Mide $7 \mathrm{~mm}$. de espesor medio. El borde es 
ligeramente saliente, el labio apuntado, mide $13^{\prime} 3 \mathrm{~cm}$ de diámetro máximo, llegando a describir una elipse. En el interior, a unos 1-1'2 mm. del labio, presenta un cordón que ofrece diez perforaciones, seis completas y cuatro incompletas. El cuello de la vasija presenta forma de trapecio con la base mayor hacia arriba y el arranque del galbo podría ser de tres cuartos de esfera o bien elíptica con el eje mayor horizontal. La porción conservada no nos permite precisar más acerca de la forma del galbo. Esta vasija, de la que se conserva más de la mitad del borde, cuello y parte del galbo, cuenta con dos asas multiforadas que comienzan directamente en el labio y finalizan en el arranque del galbo. A su vez, conserva parte de un agujero de suspensión situado a 0'9 cm. del labio y a 2' $2 \mathrm{~cm}$. de una de las asas.

La decoración consiste, mayoritariamente, en impresiones, realizadas con un instrumento agudo, y en incisiones, siendo ambas de tamaño medio y presión profunda. En cuanto a la temática, las impresiones se disponen formando dos líneas oblicuas y opuestas situadas debajo del labio, continuando, la superior, a lo largo de uno de los lados de ambas asas; este mismo tema se repite en el arranque del galbo de la vasija. Por su parte, éste ha sido decorado mediante bandas incisas verticales rellenas de impresiones iguales a las situadas en el borde y arranque del galbo (Fig. 3, $\mathbf{n}^{\circ} 3643$; lám I). Tanto las impresiones del borde como las de las asas sólo afectan a la mitad de la vasija (Lám. III). En cuanto a la decoración del galbo, la porción de vasija con que contamos, nos muestra la presencia de tres bandas incisas rellenas de impresiones, dos de ellas situadas debajo de la zona de cada asa y la tercera en el centro. Desconocemos si contaba con una cuarta banda opuesta a la central, al no haber encontrado fragmentos pertenecientes a esta parte del recipiente. Resaltamos esta disposición porque en el caso concreto de la decoración que afecta tanto al borde como a las asas, ésta coincide perfectamente con la presencia del cordón interior perforado, que sólo se presenta en un lado de la vasija. Es decir, que el cordón interior sólo aparece en la mitad de la vasija, mitad que, por el exterior, es la que ha recibido decoración en el borde y las asas (Lám. II).

$\mathrm{N}^{\circ}$ 2.- Cuatro fragmentos de una misma vasija de la que contamos con un borde y arranque de galbo, un fragmento de cuello y galbo con arranque de S.P.S. y dos fragmentos de galbo (Fig. 4, $\mathrm{n}^{\circ} 4.711$ ). La superficie exterior está bruñida y la interior alisada. Nervio de cocción y desgrasante fino. El color de la pasta pertenece a la gama de los marrones en ambas caras. La pared mide 6' $5 \mathrm{~mm}$. de espesor medio. El borde es recto, de labio plano, de $13 \mathrm{~cm}$. de diámetro y de forma elíptica. El cordón interior, que arranca directamente del labio, conserva cinco perforaciones, tres completas y restos de otras dos (Lám. IV). Los fragmentos de galbo muestran una tendencia elíptica con el eje mayor horizontal y presentan una decoración a base de líneas incisas verticales, de tamaño y presión medios, que ocupan toda la porción conservada del galbo. El S.P.S., que finaliza en el arranque del galbo, es no determinable.

$\mathrm{N}^{\circ}$ 3.- Fragmento de borde, de dirección recta, labio plano y diámetro no determinable (Fig. 7, $\mathrm{n}^{\circ} 4.712$ ). La superficie exterior es bruñida, siendo la interior de peor calidad, alisada fina. Nervio de cocción y desgrasante medio. La pared mide 5 ' $5 \mathrm{~mm}$. de espesor medio. El color es de la gama marrón en ambas caras. Carece de cualquier tipo de decoración y de S.P.S. El cordón interior, que parte directamente del labio, muestra cuatro perforaciones, dos de ellas completas (Lám. V).

$\mathrm{N}^{\circ}$ 4.- Dos fragmentos de una misma vasija, uno pertenece al borde y arranque de asa y el otro al arranque de cuello y galbo, ofreciendo también parte del asa (Fig. $7, \mathrm{n}^{\circ}$ 5.342). Superficie exterior alisada fina, interior alisada. Cocción alternante, desgrasante fino. El espesor medio de la pared mide $8 \mathrm{~mm}$. El color es de tonalidad beige-grisácea en ambas caras. El borde es saliente, de labio plano y de diámetro no determinable. Presenta un cordón interior situado a unos $5 \mathrm{~mm}$. del labio, conservando únicamente parte de una perforación. En este fragmento, al igual que en los restantes, se aprecia claramente cómo el cordón sólo se encuentra en un lado de la porción de vasija conservada, a partir del arranque del asa (Lám. V). El S.P.S. no resulta determinable al contarse tan sólo con dos arranques, pero podría tratarse de asa de cinta. La decoración, que afecta sólo al galbo, consiste en una línea incisa horizontal y en seis líneas incisas verticales que se inician a partir del arranque del asa, el tamaño de las incisiones es fino y la presión media y suave. 
$\mathrm{N}^{\circ}$. 5.- Fragmento de borde, de dirección recta, diámetro no determinable y labio redondeado apuntado. La superficie exterior es alisada fina, siendo la interior alisada. El fuego es alternante y el desgrasante muy fino. Mide 5' $5 \mathrm{~cm}$. de espesor. El color es marrón al exterior y negruzco al interior. Presenta un cordón interior que parte directamente del labio y conserva dos perforaciones. Carece de decoración y de S.P.S. (Fig. 7, nº 4.713; Lám. V).

Estos cinco ejemplares proceden de los trabajos de limpieza llevados a cabo durante 1990.

$\mathrm{N}^{\circ}$ 6.- Catorce fragmentos de borde y cuello con S.P.S. y galbo de un mismo recipiente (Fig. 8, $\mathrm{n}^{\circ} 6510$ ). Algunos de estos fragmentos proceden de los trabajos de limpieza efectuados por nosotros y otros de los trabajos de acondicionamiento de la cueva realizados entre finales de 1969 y 1971 . El borde es ligeramente saliente, el labio plano y el diámetro máximo mide $15^{\prime} 9 \mathrm{~cm}$., describiendo una elipse. La superficie exterior es espatulada, estando la interior erosionada. La cocción es alternante y el desgrasante fino. El color es beige al exterior y grisáceo al interior. El espesor medio de la pared mide $8 \mathrm{~mm}$. Directamente del borde, como si de una prolongación de éste se tratase, parte un cordón interior que presenta dos perforaciones y restos de una tercera. En la porción de vasija conservada se observa, perfectamente, cómo este cordón interior sólo se encuentra en un lado del labio (Lám. VIII), estando ausente en la otra mitad a partir del asa. Conserva, a ambos lados, dos asas multiforadas que arrancan directamente del labio y finalizan en el inicio del galbo. A una de ellas le falta sólo la parte de unión con el labio, y a la opuesta la zona de unión al galbo. En ambas se aprecia una perforación vertical en la zona de contacto con el labio. Presenta una tercera asa multiforada, horizontal, situada en el cuello.

La decoración consta de varios temas. A unos 6’5 mm. del labio y en la cara de la vasija que coincide con la situación del cordón interior, contamos con dos líneas incisas horizontales de tamaño medio y presión profunda, que parten directamente del asa; hacia la mitad del cuello, a unos $37 \mathrm{~mm}$. del labio, conserva medio «esteliforme» inciso, habiéndose realizado los rayos mediante impresiones cortas, de tamaño medio y presión profunda; al lado del asa izquierda se disponen líneas incisas verticales enmarcadas por una línea incisa horizontal, mientras que al lado del asa derecha el tema consiste en impresiones, cortas y profundas, que se hallan enmarcadas por líneas incisas que finalizan en el arranque del galbo, donde aparece una banda rellena de impresiones de la que parten haces de líneas incisas verticales que se disponen ya en el galbo, alternándose con espacios libres de decoración (Lám. VI). Este tema es idéntico al que aparece en la otra cara de la vasija, la opuesta al cordón interior, donde encontramos, además, un asa multiforada horizontal que se sitúa a $16 \mathrm{~mm}$. del labio. De este asa se conserva sólo una porción, habiéndose desprendido parte de ella, pero, por las huellas que han quedado en el cuello, debía abarcar toda la superficie del cuello comprendida entre las dos asas multiforadas verticales que parten del labio y terminan en el arranque del galbo. Debajo del asa multiforada horizontal y a unos $19 \mathrm{~mm}$. de ella, la decoración consiste en impresiones, realizadas mediante un instrumento agudo, enmarcadas por líneas incisas, que forman casi un trapecio relleno por las impresiones y que se alterna con espacios desprovistos de decoración. Este tema finaliza en el arranque del galbo, donde aparece una banda incisa rellena de impresiones. Finalmente, ya en el galbo, aparecen líneas incisas verticales que, a juzgar por el fragmento conservado, debían formar bandas alternando con zonas libres de decoración (Lám. VII). Esta vasija cuenta, por lo tanto, con tres asas multiforadas, dos de ellas verticales y la tercera horizontal, así como con diferentes temas decorativos entre los que se cuenta un esteliforme, situado en la misma cara en la que al interior aparece el cordón perforado. Suponemos que en la zona próxima al otro asa multiforada vertical se repetiría este tema decorativo, el esteliforme. El tamaño de las incisiones es ancho, excepto la que forma el esteliforme, y la presión es profunda, mientras que las impresiones son de tamaño medio y de presión profunda.

$\mathrm{N}^{\mathrm{o}}$ 7.- Dos fragmentos de borde, cuello y arranque de galbo pertenecientes a una misma vasija (Fig. 5 , $\mathrm{n}^{\circ}$. 6). La superficie exterior es de muy buena calidad, bruñida, habiendo recibido la interior un tratamiento más descuidado, alisada fina. La cocción es alternante y el desgrasante fino. Mide $7 \mathrm{~mm}$. de espesor. El 
color se encuentra dentro de la gama de los pardos tanto al exterior como al interior. El borde es ligeramente entrante, el labio apuntado y mide $13 \mathrm{~cm}$. de diámetro. En el interior, a unos $3 \mathrm{~mm}$. del labio, ofrece un cordón con seis perforaciones, cuatro completas y restos de otras dos. Cuenta con dos asas multiforadas, opuestas, que arrancan directamente del labio y finalizan en el arranque del cuello, además de un agujero de suspensión situado a $14 \mathrm{~mm}$. del labio y a $13 \mathrm{~mm}$. del arranque del asa. La decoración, realizada enteramente a base de incisiones, desarrolla un tema bastante llamativo e inusual. A unos 9' $5 \mathrm{~mm}$. del labio muestra dos líneas horizontales que, partiendo de las asas, se unen mediante una línea vertical a medida que se acercan a la zona central de la vasija. En el centro, parece repetirse este mismo tema, pero en sentido opuesto, es decir, con el eje mayor en vertical. A un lado y otro del tema central y debajo de la decoración primeramente descrita, se encuentran sendos círculos concéntricos de los que parten cuatro líneas verticales en dirección al galbo de la pieza (Láms. IX y X). El tamaño y la presión de las incisiones es medio.

$\mathrm{N}^{\circ}$ 8.- Dos fragmentos de una misma vasija de la que contamos con borde, cuello y arranque de galbo y un fragmento de arranque de cuello y galbo (Fig. $6 \mathrm{n}^{\circ}$. 7). La superficie exterior es bruñida y la interior alisada fina. La cocción es reductora y el desgrasante fino. La pared mide $5 \mathrm{~mm}$. de espesor medio. El color es pardo al exterior y negruzco al interior. El borde es saliente, el labio plano y el diámetro mide $9 \mathrm{~cm}$. La porción de borde que ha llegado hasta nosotros, ofrece un cordón interior con una perforación y parte de otra en la que se advierten restos de colorante, ocre rojo. Este cordón interior arranca directamente del labio. Cuenta con dos S.P.S., un asa y un agujero de suspensión. El asa es de cinta vertical, de sección rectangular, perforada en ambos extremos, tanto en la zona de contacto con el labio como en la del arranque del galbo. El agujero de suspensión está situado a $9 \mathrm{~mm}$. del labio, muy pegado al asa, y en la cara que coincide con el cordón interior perforado. La decoración consta de dos líneas incisas, paralelas, situada la superior a 6' 5 $\mathrm{mm}$. del labio. En el centro del cuello muestra tres impresiones que describen un pequeño arco y, ya en el galbo, marcado por una carena, se dispone una línea incisa horizontal de la que casi parten tres verticales. Finalmente, debajo del asa parten cinco líneas incisas verticales. La presión ejercida y el tamaño de estas incisiones es medio (Lám. XI).

$\mathrm{N}^{\circ}$ 9.- Fragmento de borde y cuello (Fig. 6, $\mathrm{n}^{\circ} .8$ ). La superficie exterior ha recibido un acabado muy bueno, espatulado, siendo la interior alisada fina. La cocción es alternante y el desgrasante fino. Mide 6' 5 $\mathrm{mm}$. de espesor medio. El color es de la gama marrón en ambas caras. El labio es plano, de borde recto y de $9 \mathrm{~cm}$. de diámetro. Ofrece un cordón interior que parte directamente del labio, conservando cinco perforaciones. No está asociado a decoración ni a S.P.S. (Lám. V).

$\mathrm{N}^{\circ}$. 10.- Fragmento de borde (fig. $6, \mathrm{n}^{\circ} .9$ ). La superficie exterior es bruñida y la interior alisada fina. La cocción es reductora y el desgrasante fino. El espesor de la pared mide $6 \mathrm{~mm}$. El color es negruzco al exterior y pardo al interior. El borde es recto, de labio redondeado-apuntado y diámetro no determinable. El cordón interior se sitúa a unos 3'5 mm. del labio, conservando tres perforaciones. No presenta decoración ni S.P.S. (Lám. V).

$\mathrm{N}^{\circ}$ 11.- Fragmento de borde, cuello y arranque del galbo (Fig. $7, \mathrm{n}^{\circ} 11$ ). La superficie exterior es espatulada, casi bruñida, siendo la interior alisada fina. El desgrasante es fino y la cocción alternante. Mide $5 \mathrm{~mm}$. de espesor y el color es beige al exterior y negruzco al interior. El labio es plano, de dirección recta y mide $9 \mathrm{~cm}$. de diámetro. Conserva un asa multiforada, incompleta, que parte del labio. Presenta en todo el perímetro del labio conservado un cordón interior, que arranca del asa, con tres perforaciones completas y restos de otras dos. Aproximadamente a $1 \mathrm{~cm}$. del labio, cuenta con una línea incisa horizontal que queda algo enmascarada al haberse desprendido parte de la superficie exterior de la vasija (Lám. XI). Se encuentra depositado en los fondos del M.A.P. de Córdoba y no cuenta con referencia alguna de su lugar de procedencia dentro de la cueva, formando parte del lote de material entregado tras realizar las obras de acondicionamiento. 
$\mathrm{N}^{\circ}$ 12.- Fragmento de borde, cuello y arranque de galbo procedente de la Cueva Negra (Rute) (Fig. 9 , $n^{\circ}$. 49). La superficie exterior es alisada muy fina y la interior alisada fina. La cocción es alternante y el desgrasante fino. La pared mide $7 \mathrm{~mm}$. de espesor medio. El color es de la gama marrón en ambas caras. El borde es recto, de labio plano y de 9' $6 \mathrm{~cm}$. de diámetro. Aproximadamente a 1' $1 \mathrm{~mm}$. del labio presenta un cordón interior que conserva dos perforaciones. Cuenta con asas multiforadas que parten directamente del labio y finalizan en el arranque del galbo y con un agujero de suspensión situado a 1'3 mm. del labio. La decoración, que afecta sólo al galbo en la porción de vasija conservada, consiste en ángulos incisos en serie situados en el arranque del galbo y en una línea horizontal de la que parten seis líneas oblicuas en sentido ascendente. El tamaño de estas incisiones es ancho y la presión ejercida es profunda. Esta decoración se distribuye coincidiendo con zona en la que se localiza el cordón interior. Agradecemos a D. Juan Ruiz el haber puesto a nuestra disposición esta pieza.

$\mathrm{N}^{\mathrm{o}}$ 13.- Fragmento de borde y arranque de cuello procedente de la Cueva del Muerto (Carcabuey) (Fig. $\left.5, n^{\circ} .13\right)$. El borde es recto, de labio redondeado y de $13^{\prime} 4 \mathrm{~cm}$. de diámetro. La superficie exterior es alisada fina y la interior es alisada. El fuego es de nervio de cocción y el desgrasante es medio, mide $8 \mathrm{~mm}$. de espesor medio y el color es marrón en ambas caras. Presenta un cordón interior, situado a $6 \mathrm{~mm}$. del labio, que muestra tres perforaciones completas y restos de una cuarta. El fragmento que se conserva ofrece un pequeño mamelón, poco pronunciado, a unos $5 \mathrm{~mm}$. de labio del que parten siete líneas incisas verticales y dos líneas, también incisas, horizontales, debajo de las cuales se encuentra representado un esteliforme inciso. En el extremo opuesto de la porción de vasija con que contamos, la decoración debía ser igual, puesto que aparecen dos líneas incisas y debajo medio esteliforme. El tamaño y la presión, tanto de las líneas como de los esteliformes, es medio. Como S.P.S., sólo se ha conservado el mamelón redondeado macizo situado debajo del labio. Agradecemos a D. Rafael Bermudez las facilidad prestada para su estudio.

\section{BIBLIOGRAFÍA}

ACOSTA, P., PELliCER, M (1990): La Cueva de la Dehesilla (Jerez de la Frontera. Las Primeras Civilizaciones Productoras en Andalucía Occidental. Jerez.

ARRIBAS, A., MOLINA, F., SAEZ, L., TORRE, F. DE LA, AGUAYO, P., NAJERA, T. (1979): «Excavaciones en Los Millares (Santa Fe, Almería). Campañas de 1978 y 1979». C.P.U.Gr. 4: 61-109. Granada.

ASQUERINOFERNANDEZ, Mª.D. (1986-87): «<Cueva de los Mármoles> (Priego de Córdoba), avance de las campañas de excavación 1982/1986». IFIGEA III-IV: 239-249. Córdoba.

BALDOMERO NAVARRO, A (1978): «Noticia del hallazgo de un vaso Eneolítico». Anejos de BAETICA I: 167-170. Málaga.

BERNIER, J.; FORTEA, F.J (1968-69): «Nuevas pinturas esquemáticas en la provincia de Córdoba. Avance a su estudio.» Zephyrus, XIX-XX, Salamanca, 143-164.

CARRASCO, J.; CARRASCO, E.; MEDINA, J.; TORRECILLAS, J.F (1985): El Fenómeno Rupestre Esquemático en la Cuenca Alta del Guadalquivir. I: Las Sierras Subbéticas. Prehistoria Giennense, $\mathrm{n}^{\circ} 1$.

DELIBES, G.; FERNANDEZ-MIRANDA, M.; FERNANDEZ-POSSE, Mª.D.; MARTIN, C. (1986): «El poblado de Almizaraque.». Homenaje a L. Siret: 167-177. (Cuevas de Almanzora, 1985). Sevilla.

FERRER PALMA, J.E (1977): «La Necrópolis Megalítica de Fonelas (Granada). El Sepulcro <Domingo 1> y sus Niveles de Enterramiento. C.P.U.Gr, n $2: 173-190$.

FERRER, J.E.; MARQUES, I (1978): «Avance de las campañas arqueológicas realizadas en la <Cueva de las Palomas> Teba (Málaga).»Anejos de BAETICA I: 195-206. Málaga. 
GAVILAN CEBALLOS, B (1986): «<Idolo> de hueso de la Cueva del Muerto (Carcabuey, Córdoba)». E.P.C. 1: 71-75. Córdoba 1987: «Grafito sobre cerámica procedente de la Cueva del Muerto de Carcabuey (Córdoba)». E.P.C. 2: 95-99. Córdoba 1989 a: «Paralelismo entre la decoración cerámica y el Arte Esquemático parietal: vasija de la Cueva de la Murcielaguina (Priego de Córdoba)». XIX C.N.A.: 229-236. Zaragoza 1989 b: El Neolítico en el Sur de Córdoba. Análisis sistemático de las primeras culturas productoras. Anexos de E.P.C.. 2 vols, 823 págs, 290 figs. Univ. de Córdoba, 1991: «Avance preliminar sobre la excavación arqueológica de urgencia en la Cueva de los Murciélagos de Zuheros (Córdoba)». ANTIQVITAS 2: 17-25. Priego de Córdoba.

GAVILAN CEBALLOS, B. y VERA RODRIGUEZ, J.C (1992): «Breve avance sobre los resultados obtenidos en la excavación arqueológica de urgencia en la Cueva de los Murciélagos de Zuheros (Córdoba)». ANTIQVITAS 3: 23-30. Priego de Córdoba.

GONÇALVES, V.S (1989): Megalitismo e metalurgia no Alto Algarve Oriental, uma aproximaÇao integrada. 2 vols. INIC/UNIARQ. Lisbo.

HURTADO, V (1978): «Los ídolos del Calcolítico en el occidente peninsular». Habis 9: 357-364. Sevilla.

MARTIN, D. y CAMALICH, Ma .D (1982): «La <Cerámica simbólica> y su problemática (Aproximación a través de los materiales de la Colección L. Siret)». C.P.U.Gr. 7: 267-306. Granada.

McPHERSON, G 1870: La Cueva de la Mujer (Alhama, Granada). Cádiz

MENJIBAR, J.L., MUÑOZ, M.J. y GONZALEZ-RIOS, M.J (1981): «Nuevos hábitats neolíticos en el sector oriental de Sierra Gorda (Granada)». Antropología y Paleoecología Humana 2: 55-75. Granada.

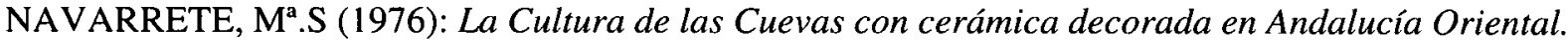
2 vols, 413+188 págs, CDIV Láms. Granada.

NAVARRETE, M.S. y CARRASCO, J (1978): «Neolítico en la provincia de Jaén». C.P.U.Gr. 3: 45-66. Granada

OLARIA, C 1977: Las cuevas de Los Botijos y de La Zorrera en Benalmádena. Patronato Museo de Benalmádena. 82 págs. Málaga.

PELLICER, M(1964): El Neolítico y el Bronce de la Cueva de la Carigüela de Piñar(Granada). T.P. XV. 71 págs. Madrid.

PELLICER, M. y ACOSTA, P (1986): «Neolítico y Calcolítico de la Cueva de Nerja». La Prehistoria de la Cueva de Nerja (Málaga). Jordá Pardo, F.J. editor. Patronato de la Cueva de Nerja: 339-450. Málaga.

QUADRA, A.M ${ }^{\mathrm{a}}$. DE LA y VICENT, A.M (1964): «Informe de las excavaciones en la Cueva de los Murciélagos de Zuheros (Córdoba). Primera campaña, 1962». N.A.H. IV, 1-3: 68-72. Madrid.

SHUBART, H (1965): «As duas fases de ocupaÇao do túmulo de cúpula do Monte do Outeiro, nos alrredores de Aljustrel». Revista de Guimaraes LXXV: 195-210. Guimaraes.

VICENT, A.Ma. y MUÑOZ, A.M (1973): Segunda campaña de excavaciones en la Cueva de los Murciélagos (Zuheros, Córdoba). E.A.E. 77. Madrid.

GAVILAN, B. y VERA, J.C. "Cerámicas con decoración simbólica y cordón interior perforado procedentes de varias cuevas situadas en la Subbética cordobesa". 

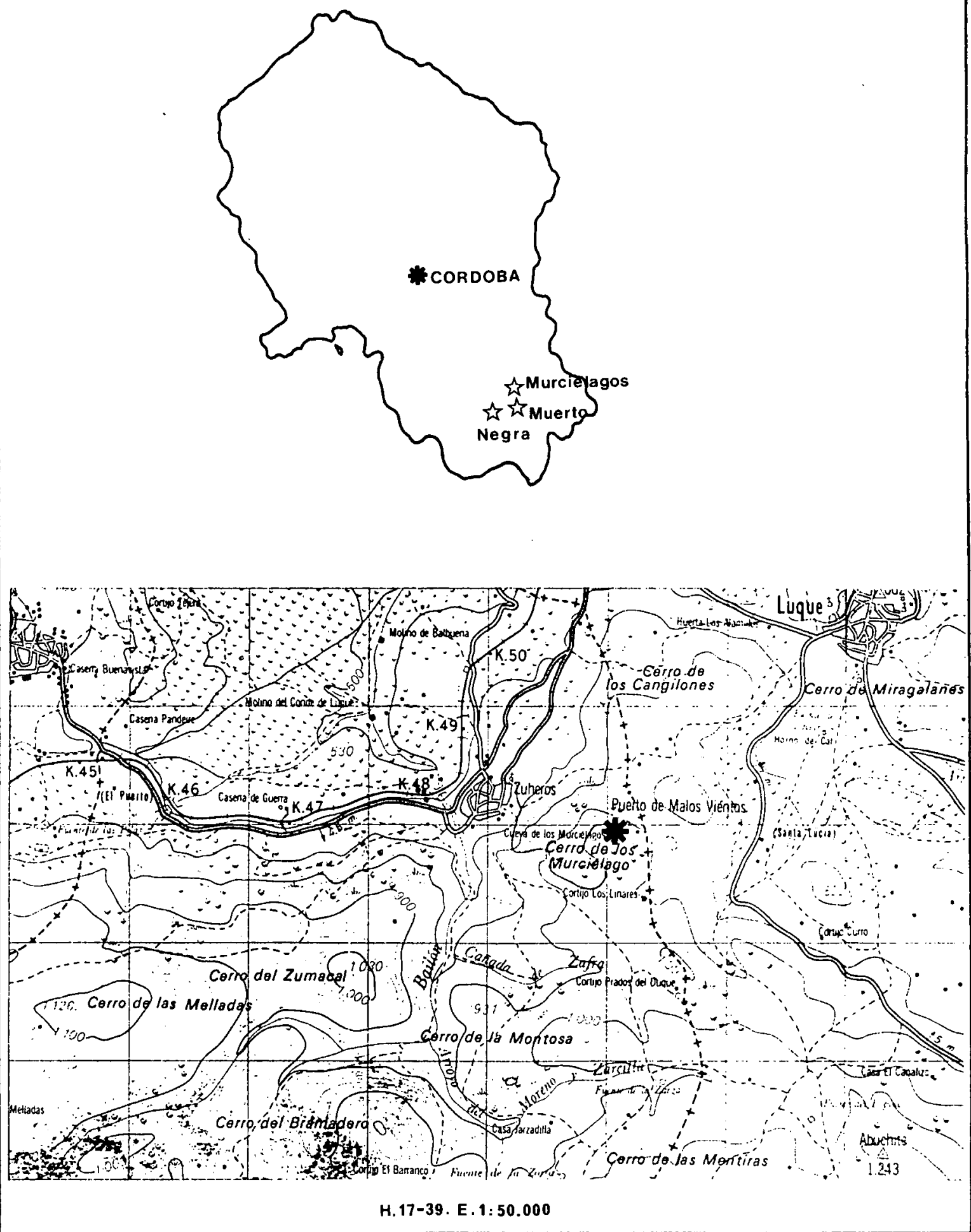

FIGURA 1.-Situación de las cavidades en la provincia de Córdoba y localización de la Cueva de los Murciélagos de Zuheros.

SPAL 2 (1993)

ISSN: 1133-4525 ISSN-e: 2255-3924 http://dx.doi.org/10.12795/spal.1993.i2.03 


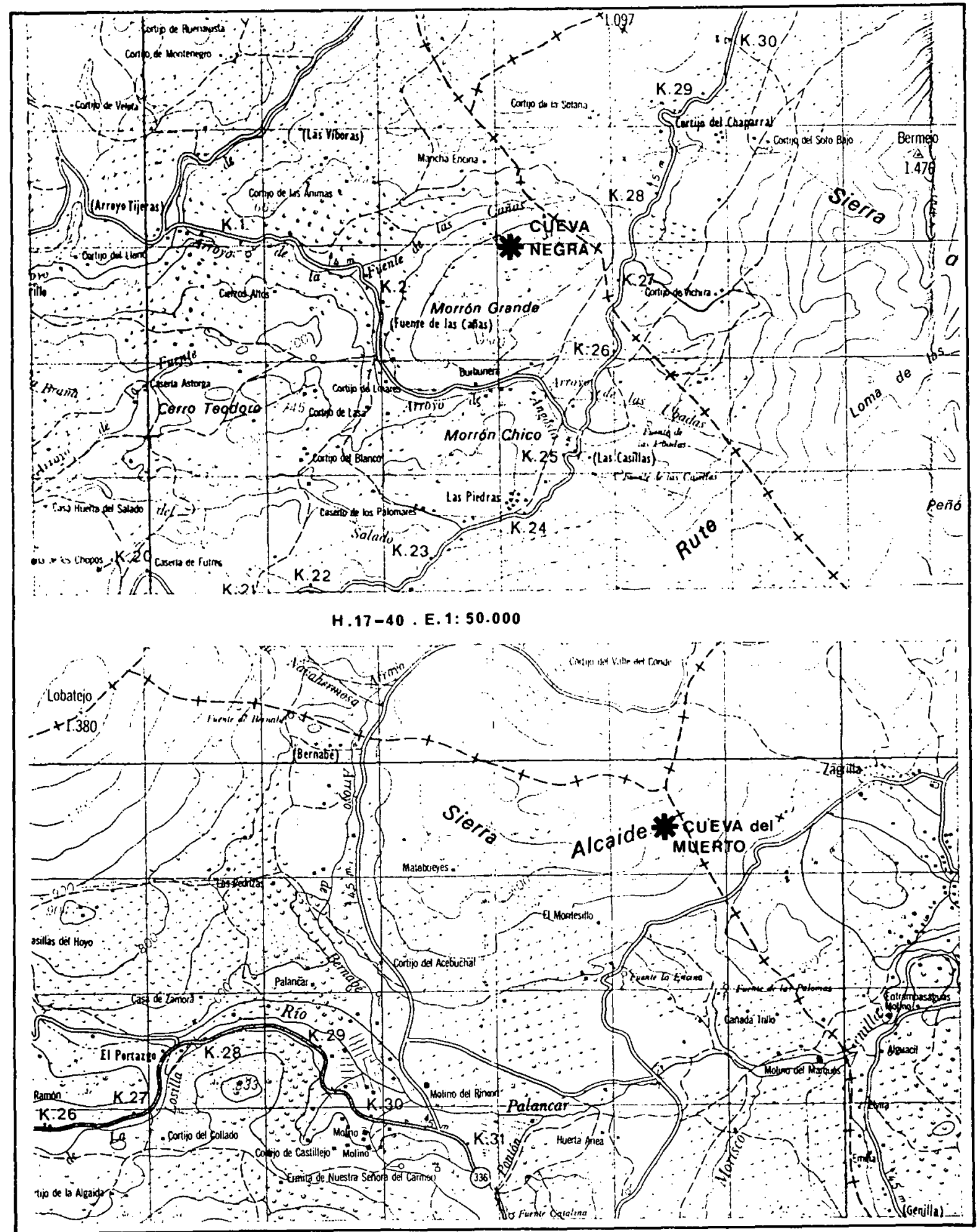

FIGURA 2.-Localización de Cueva Negra (Rute) y Muerto (Carabuey). 


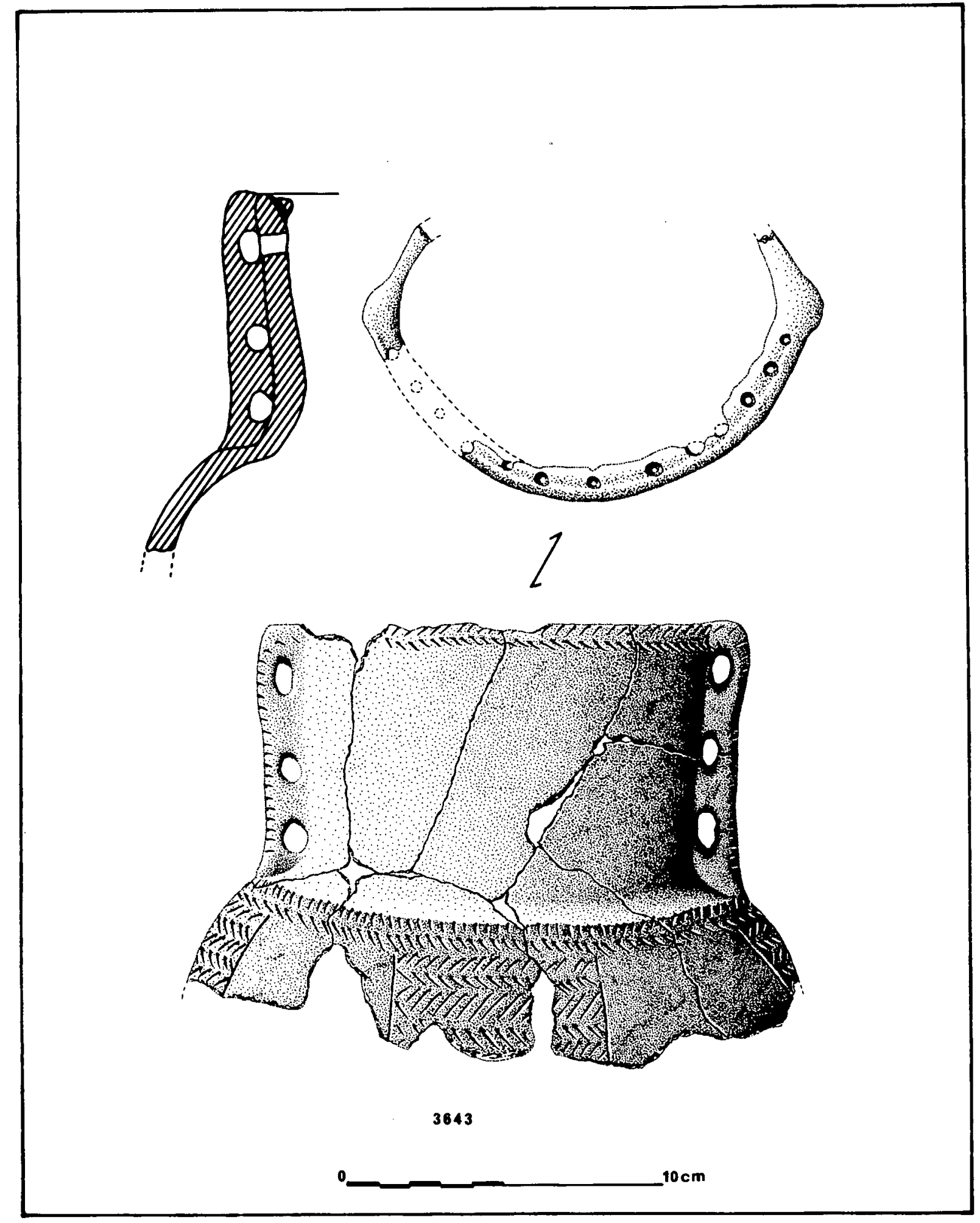

FIGURA 3.-Recipiente n.` 1. Murciélago de Zuheros. 


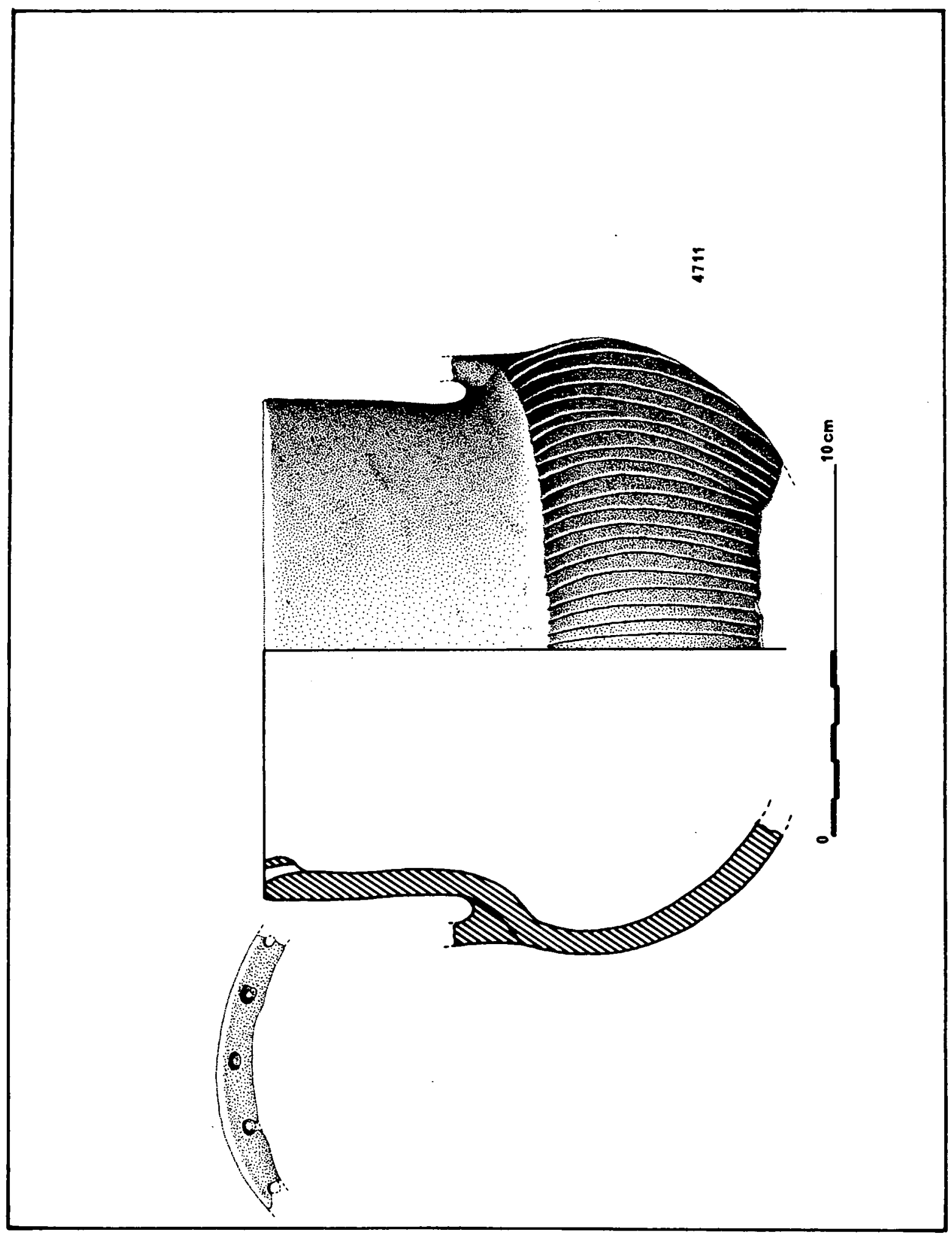

FIGURA 4.-Reconstrucción del recipiente n. ${ }^{\circ}$ 2. Murciélagos de Zuheros. 


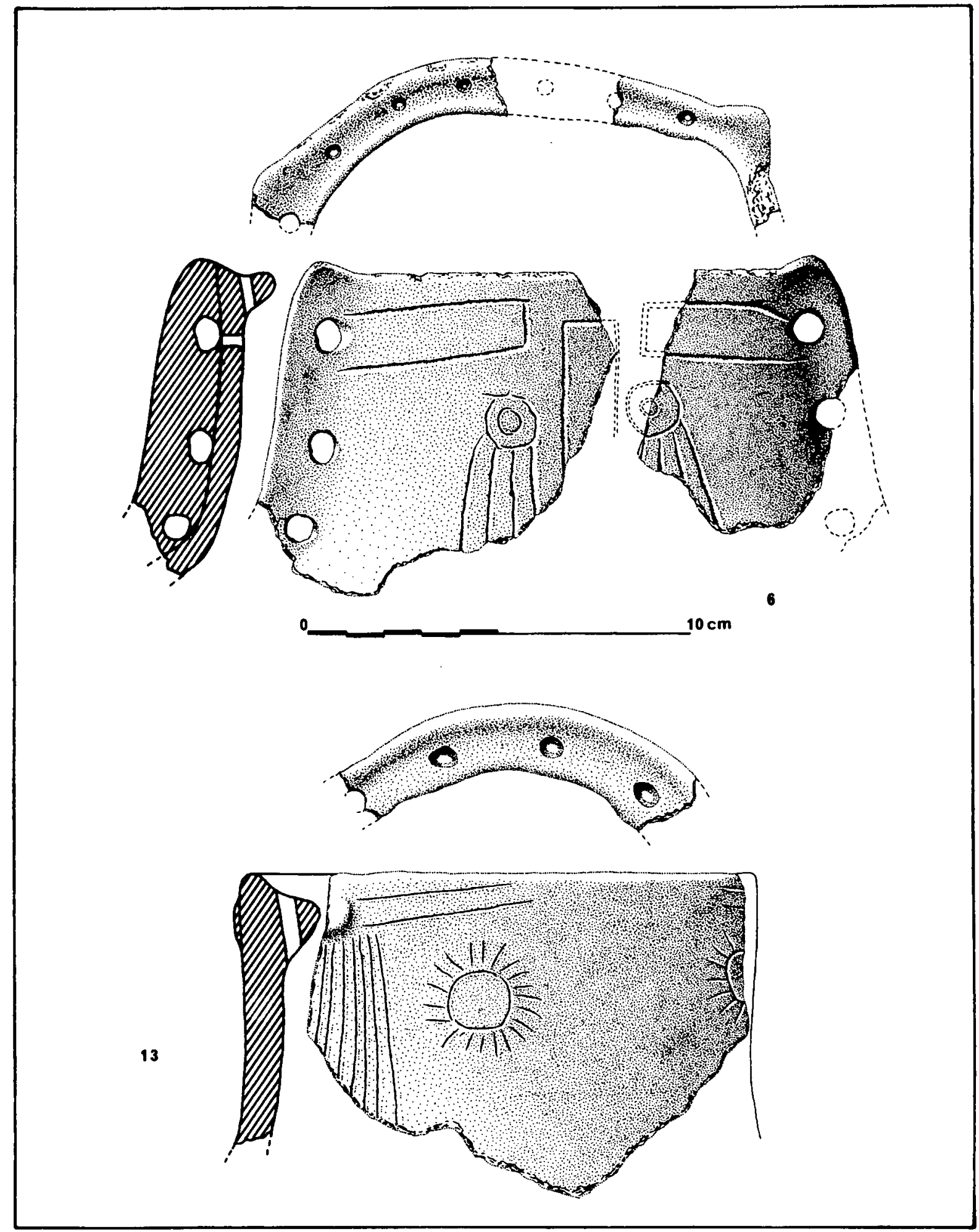

FIGURA 5.-Recipientes $n .^{\circ} 7$ del catálogo (n. ${ }^{\circ}$ 6), de Murciélagos y n. ${ }^{\circ} 13$ (n. $\left.{ }^{\circ} 13\right)$ de la Cueva del Muerto. Carcabuey. 


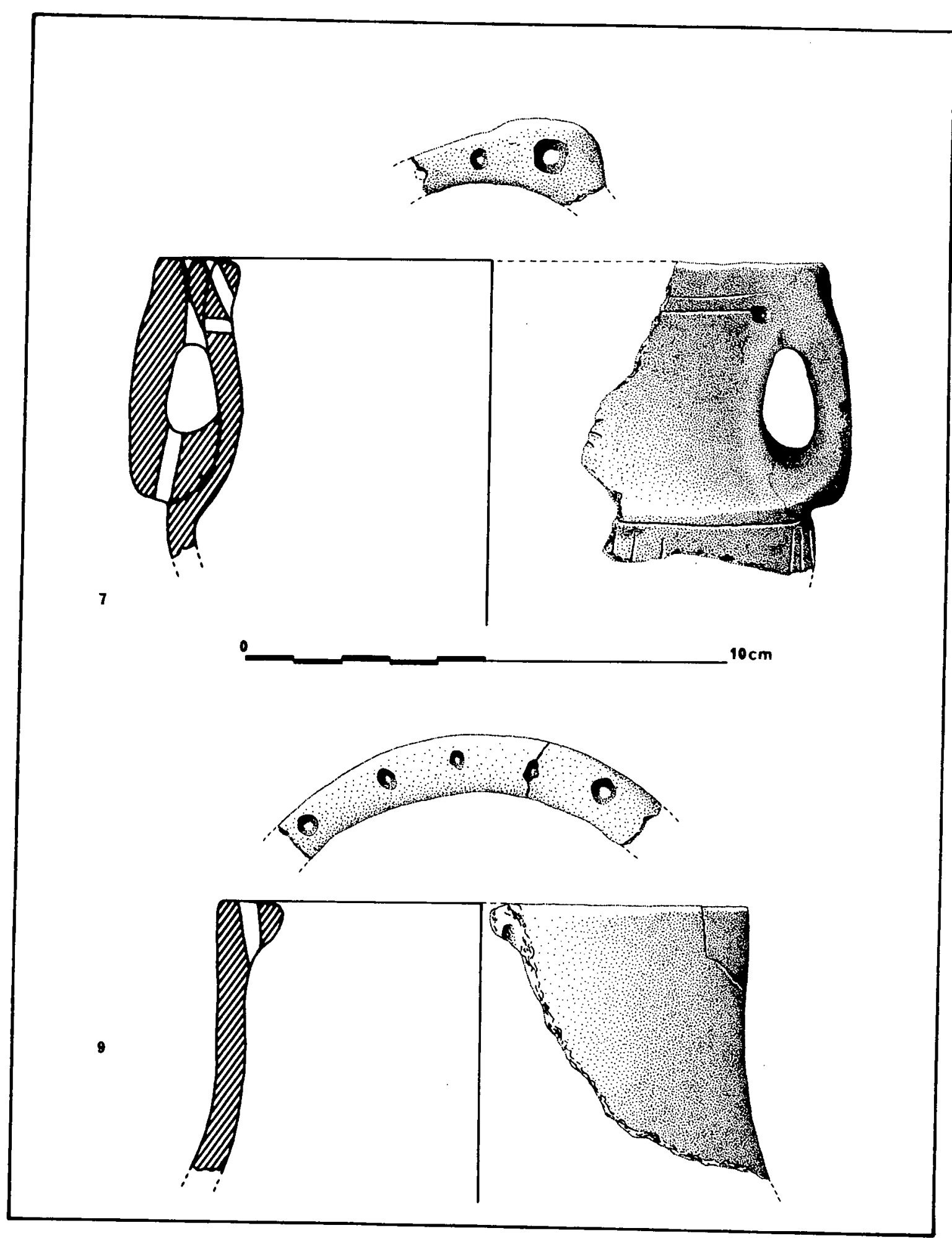

FIGURA 6.-Recipientes $n .^{\circ} 8\left(n .^{\circ} 7\right)$ y n. $10\left(n .^{\circ} 9\right)$ del catálogo. 


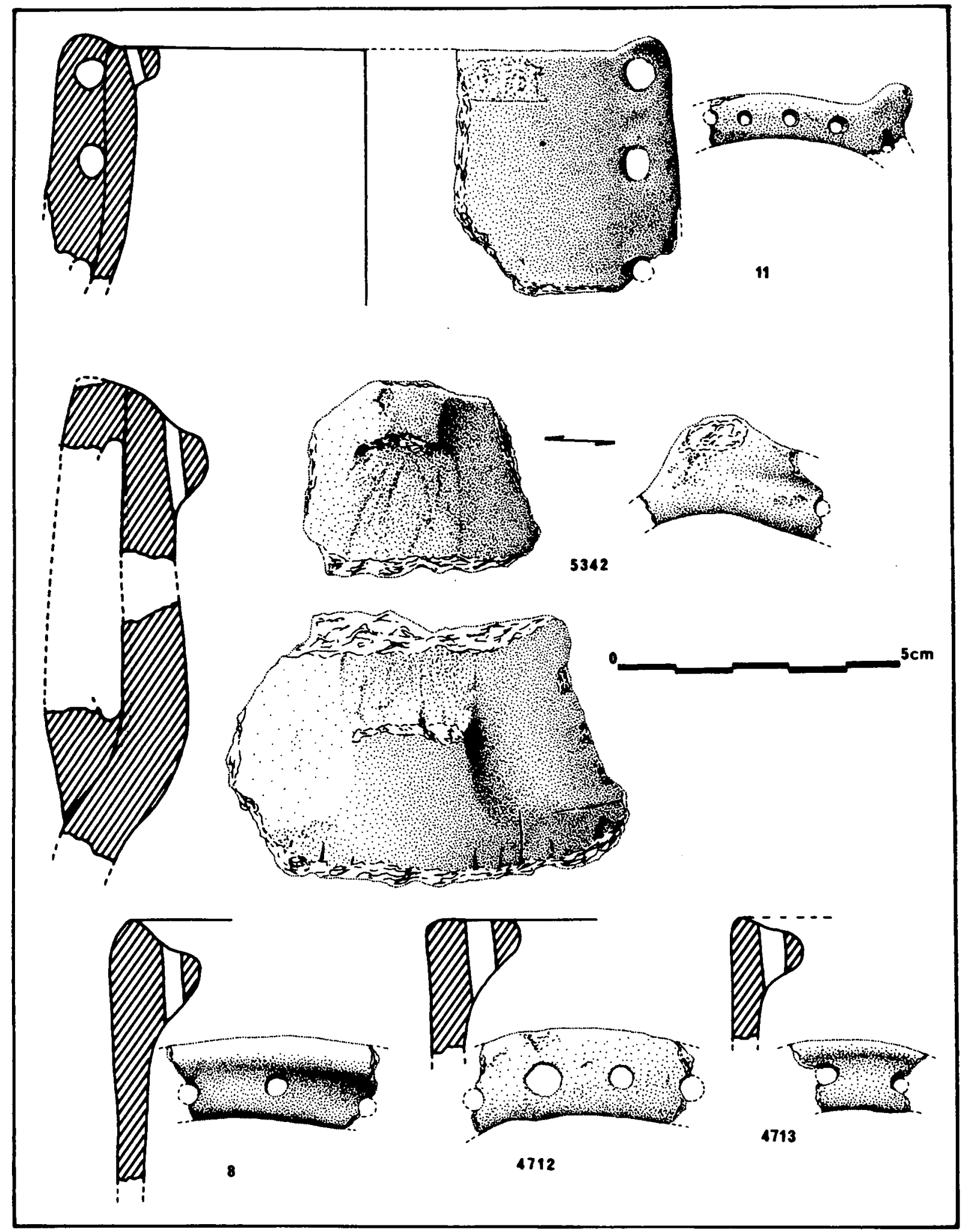

FIGURA 7.-Fragmentos $n .^{\circ} 11\left(n .^{\circ} 11\right), 4\left(n .^{\circ} 5.342\right), 9\left(n .^{\circ} 8\right), 3$ (n. $\left.{ }^{\circ} 4.172\right)$ y 5 (n. $\left.{ }^{\circ} 4.713\right)$ del catálogo. 


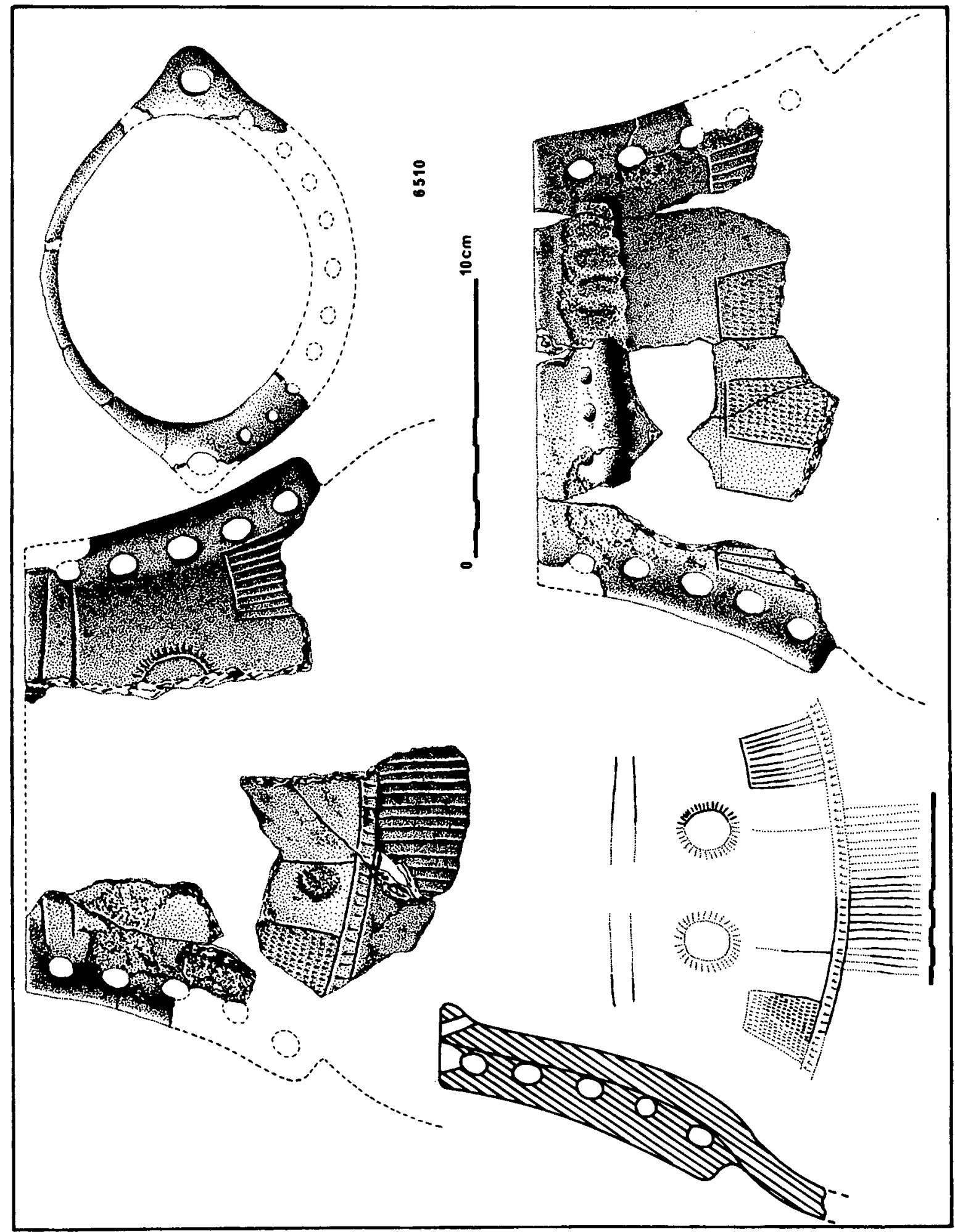

FIGURA 8.-Recipiente n. 6 y desarrollo de su decoración. 


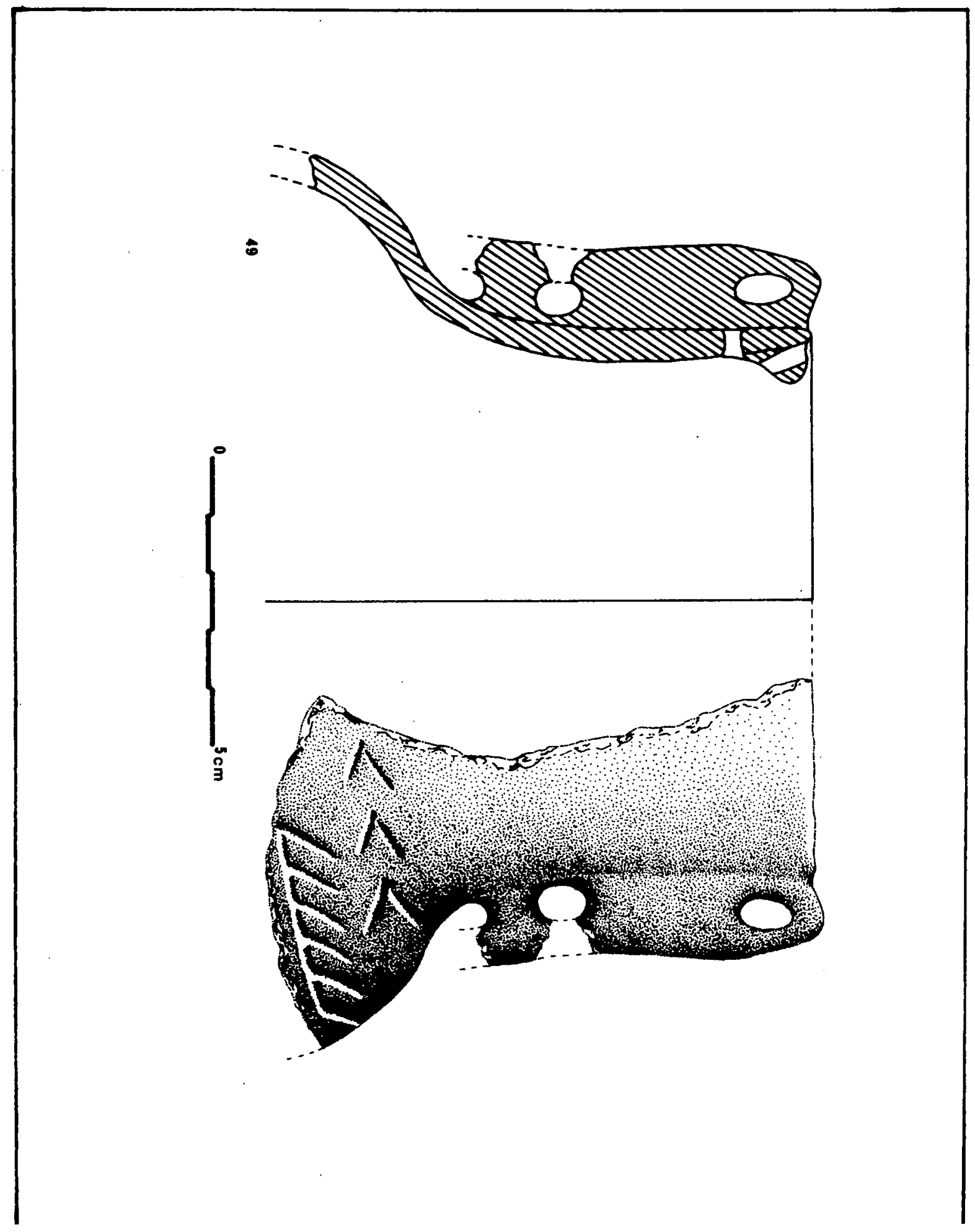

FIGURA 9.-Recipiente n. ${ }^{\circ}$ 12. Cueva Negra de Rute. 


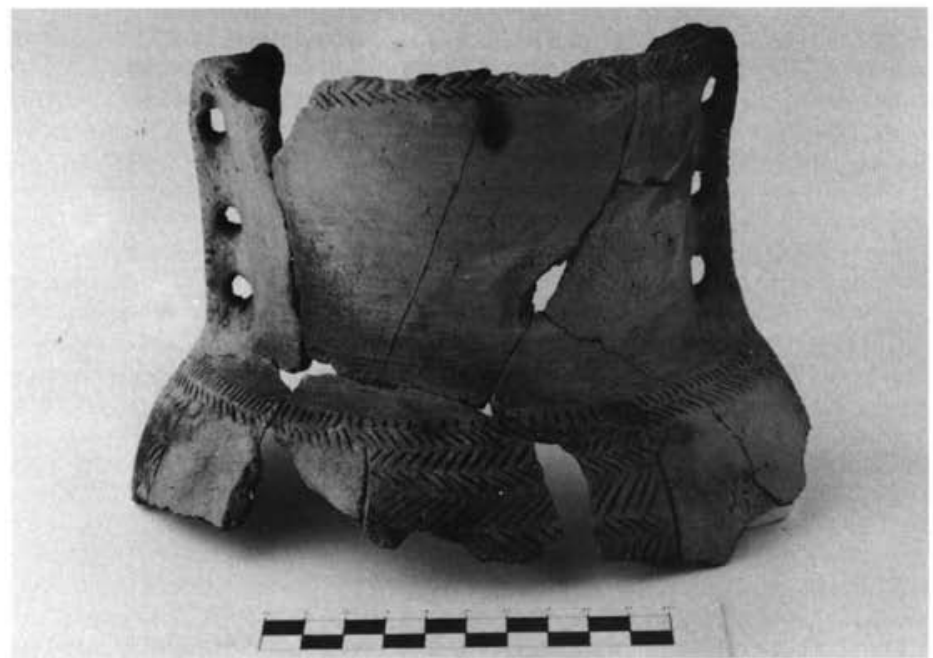

I.-Recipiente n." 1. Vista frontal desde el lado que presenta el cordón perforado por el interior. (Foto Nanuk).

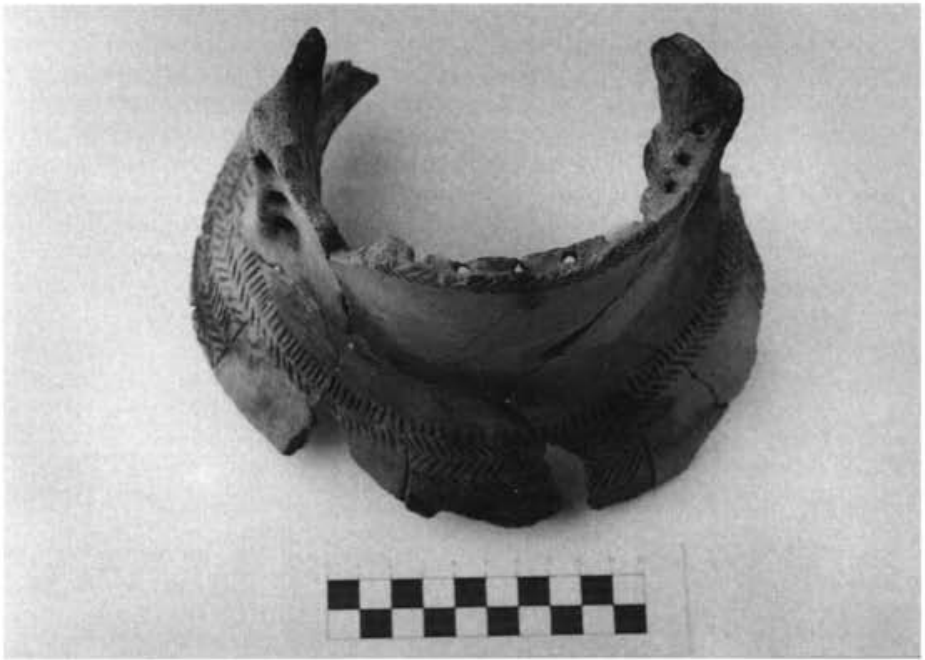

II.-Vista superior del recipiente n." 1. Se observa cómo el cordón perforado parte de un asa y finaliza en la otra. (Foto Nanuk).

ISSN: 1133-4525 ISSN-e: 2255-3924

SPAL 2(1993)

http://dx.doi.org/10.12795/spal.1993.i2.03 


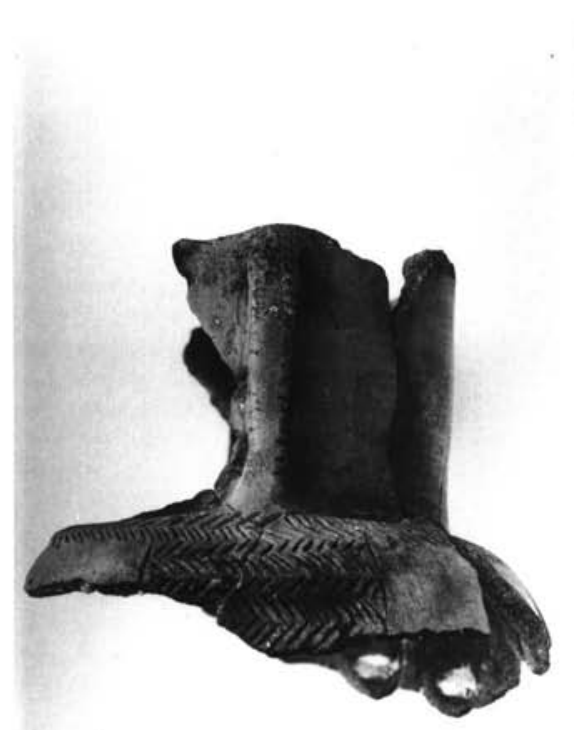

III.-Vista lateral del recipiente $n .{ }^{\circ} 1$, donde se aprecia que la decoración de borde de asa, sólo afecta a la misma mitad de la vasija en que se sitúa el cordón perforado. (Foto Nanuk).

IV.-Fragmentos que han permitido reconstruir el recipinte n.' 2 . (Foto Nanuk).
ISSN: 1133-4525 ISSN-e: 2255-3924

http://dx.doi.org/10.12795/spal.1993.i2.03 


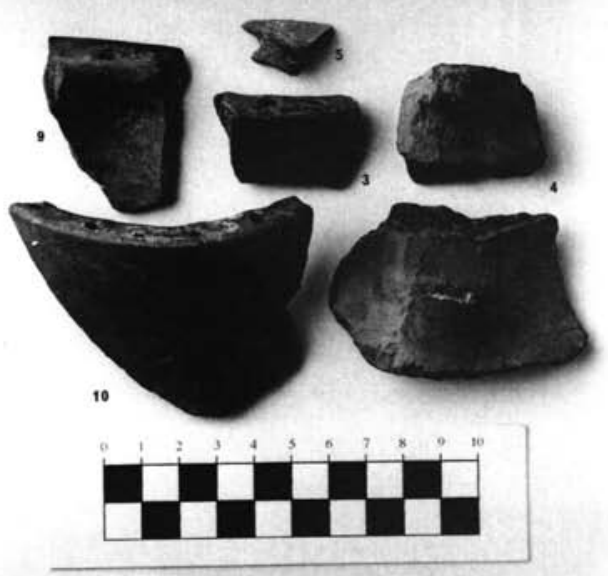

V.-Fragmentos de los recipientes n. ${ }^{\circ}$, 4, 5, 9 y 10 (Foto Nanuk).

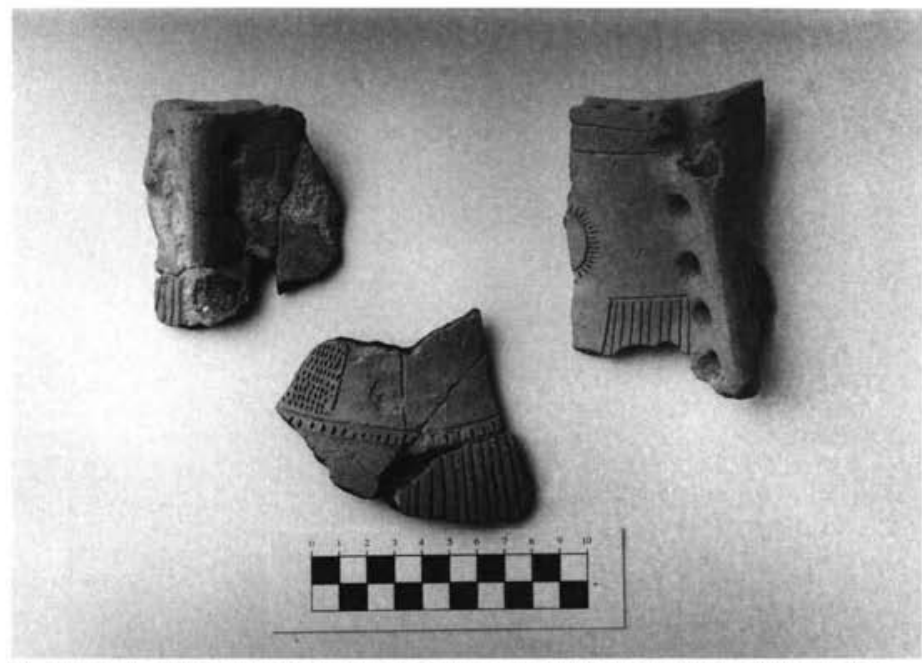

VI.-Recipiente n. ${ }^{\circ}$. Fragmentos conservado del lado que presenta decoración simbólica y cordón interior perforado. (Foto Nanuk).

ISSN: 1133-4525 ISSN-e: 2255-3924

SPAL 2 (1993)

http://dx.doi.org/10.12795/spal.1993.i2.03 


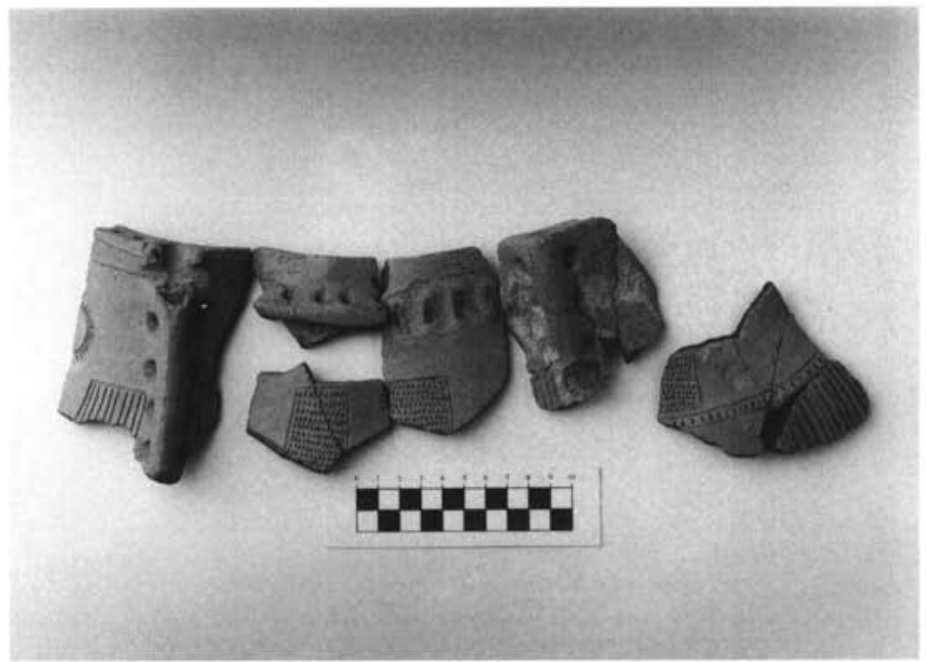

\section{VII.-Desarrollo total del recipiente n. ${ }^{\circ}$ 6. (Foto Nanuk).}

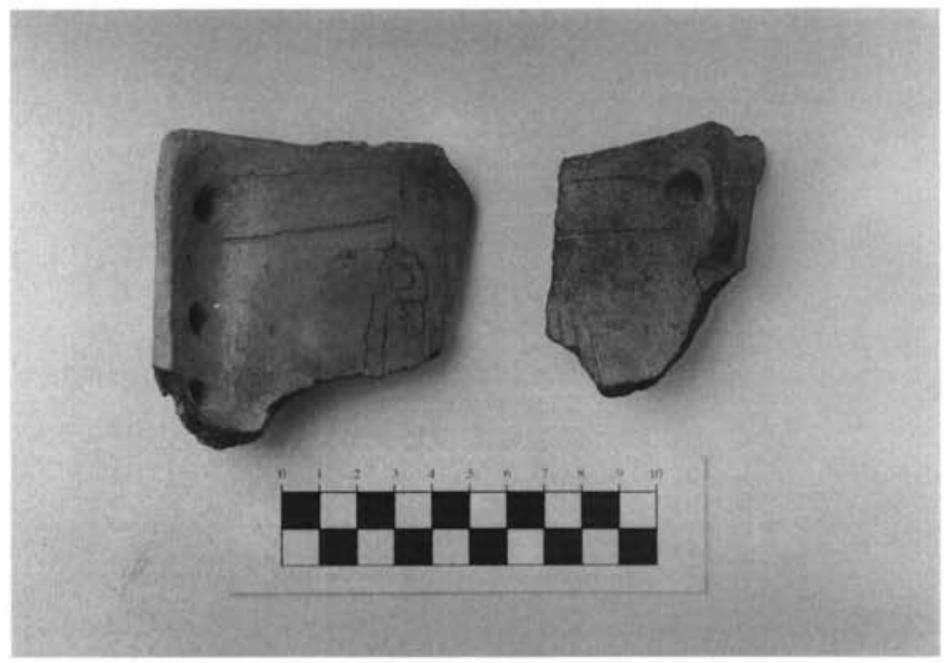

IX.-Recipiente n." 7, en el que destaca, por su claridad, el tema oculado. (Foto Nanuk). 


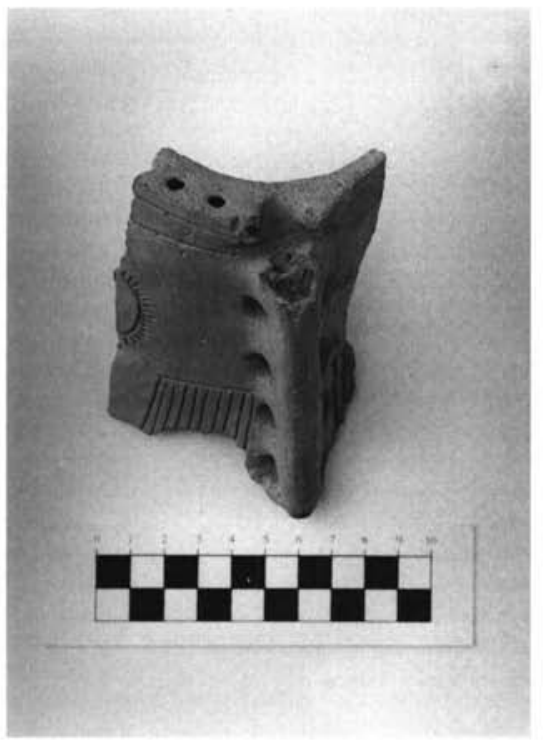

VIII.-Detalle del recipiente $n .^{\circ} 6$,

donde se observa que el cordón

perforado sólo afecta a la mitad

del perímetro interior

de la vasija.

(Foto Nanuk).

X.-Detalle del tema oculado de la vasija n. ${ }^{\circ} 6$. (Foto Nanuk).

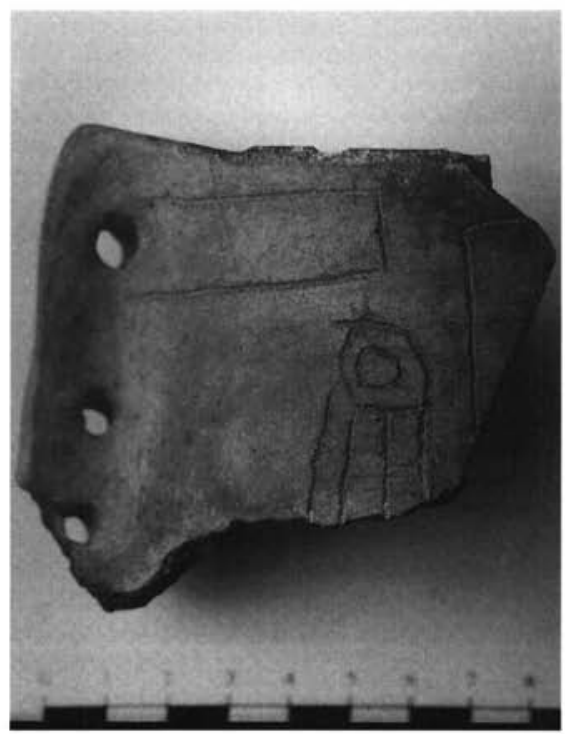




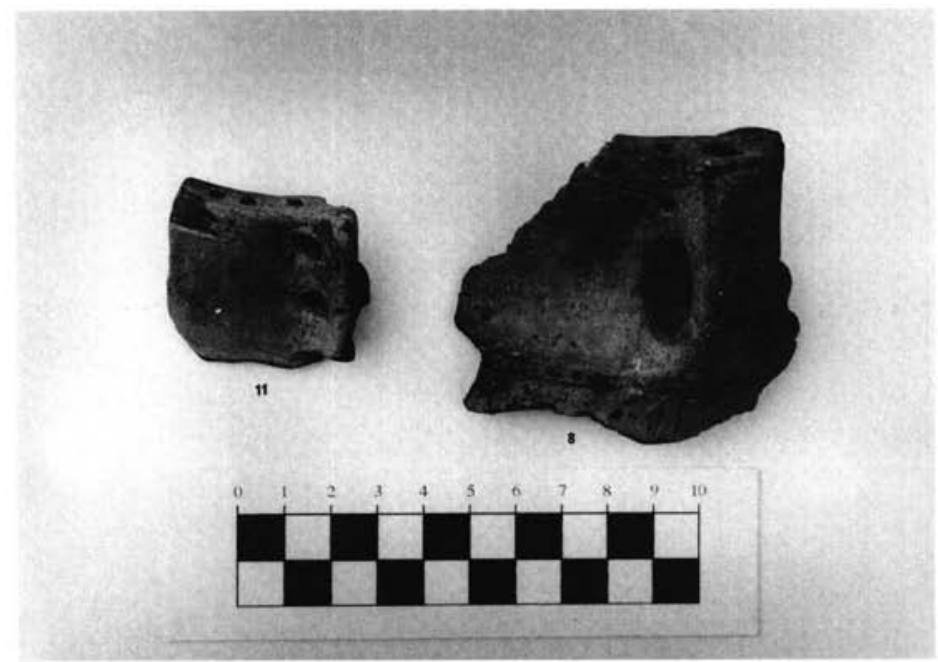

XI.-Fragmentos n.*7 y 11 . Nótese en el segundo, las tres impresiones formando un arco sobre el cuello y junto a la rotura izquierda. (Foto Nanuk). 